\title{
Involvement of aquaglyceroporins in energy metabolism in health and disease
}

\author{
Giuseppe Calamita ${ }^{\mathrm{a}}$, Christine Delporte ${ }^{\mathrm{b}, *}$ \\ a Department of Biosciences, Biotechnologies and Biopharmaceutics, University of Bari “Aldo Moro", Bari, Italy \\ ${ }^{\mathrm{b}}$ Laboratory of Pathophysiological and Nutritional Biochemistry, Université Libre de Bruxelles, Brussels, Belgium
}

\section{A R T I C L E I N F O}

\section{Article history:}

Received 25 January 2021

Received in revised form

23 February 2021

Accepted 1 March 2021

Available online 6 March 2021

\section{Keywords:}

Aquaporins

Energy metabolism

Adipose tissue

Endocrine pancreas

Liver

Clinical disorders

Drug targets

\begin{abstract}
A B S T R A C T
Aquaglyceroporins are a group of the aquaporin ( $\mathrm{AQP}$ ) family of transmembrane water channels. While AQPs facilitate the passage of water, small solutes, and gases across biological membranes, aquaglyceroporins allow passage of water, glycerol, urea and some other solutes. Thanks to their glycerol permeability, aquaglyceroporins are involved in energy homeostasis. This review provides an overview of what is currently known concerning the functional implication and control of aquaglyceroporins in tissues involved in energy metabolism, i.e. liver, adipose tissue and endocrine pancreas. The expression, role and (dys)regulation of aquaglyceroporins in disorders affecting energy metabolism, and the potential relevance of aquaglyceroporins as drug targets to treat the alterations of the energy balance is also addressed.
\end{abstract}

() 2021 Published by Elsevier B.V.

\section{Contents}

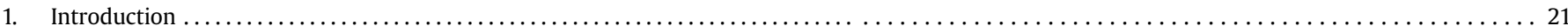

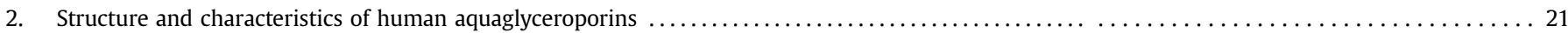

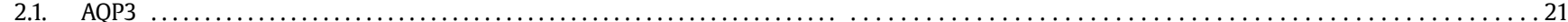

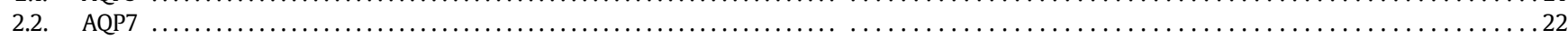

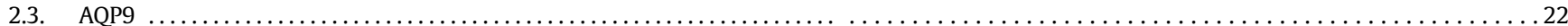

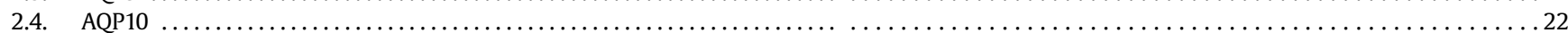

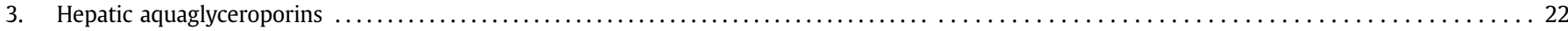

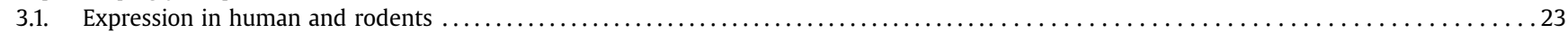

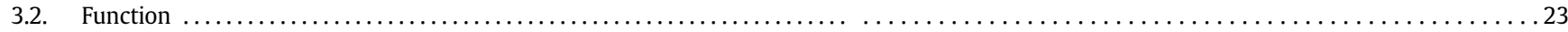

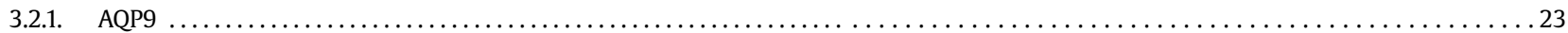

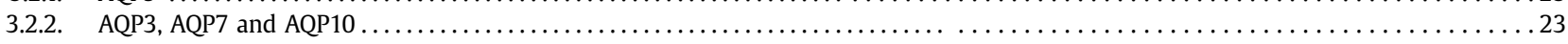

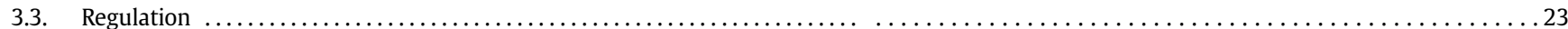

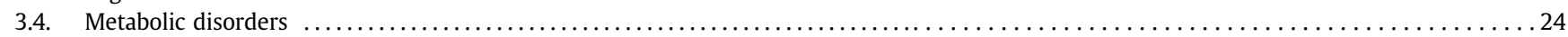

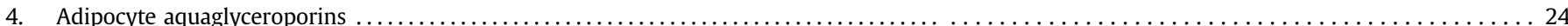

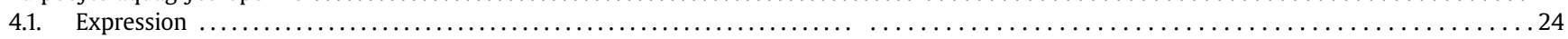

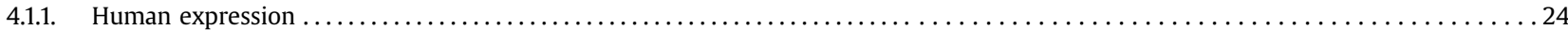

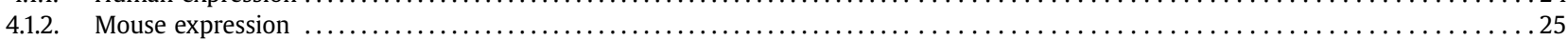

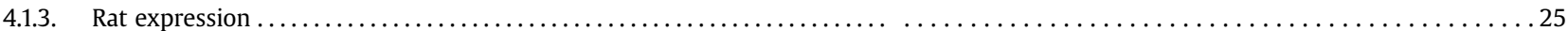

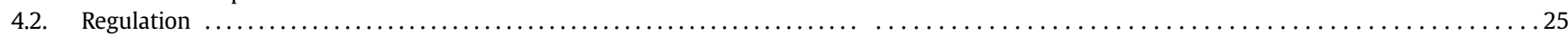

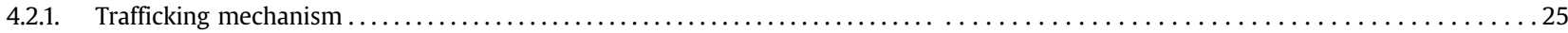

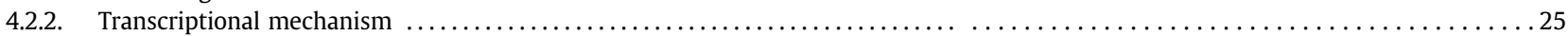

\footnotetext{
* Corresponding author.

E-mail address: christine.delporte@ulb.be (C. Delporte).
} 


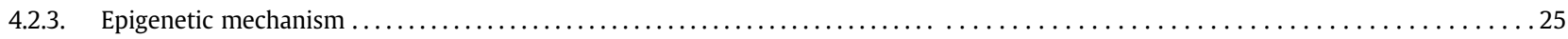

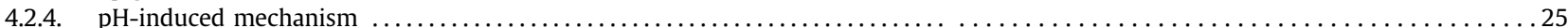

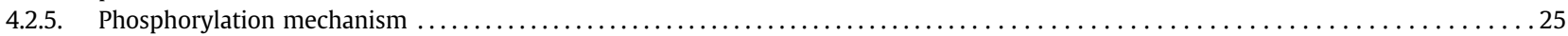

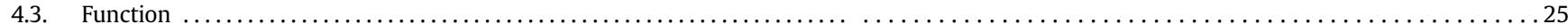

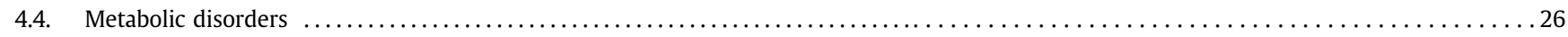

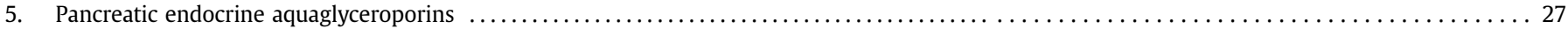

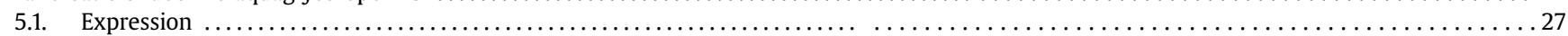

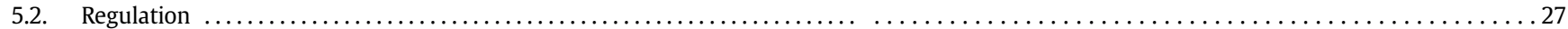

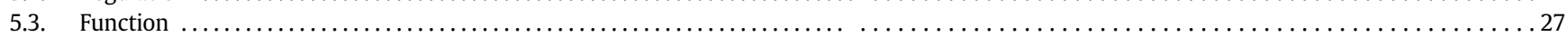

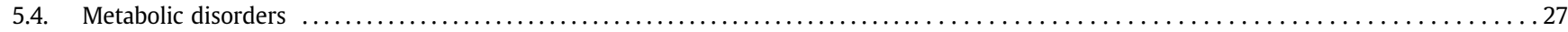

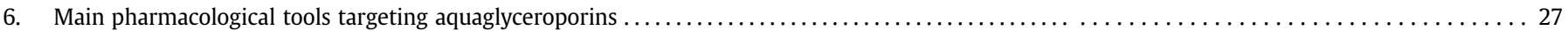

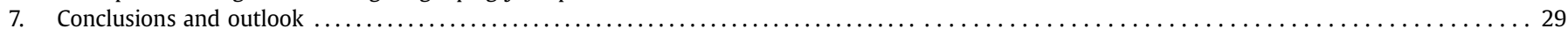

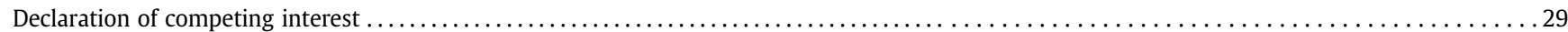

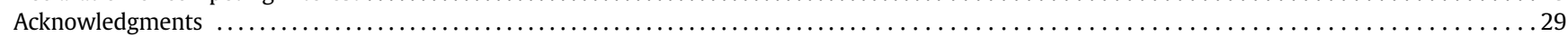

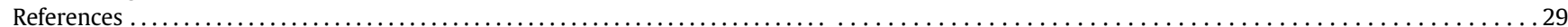

\section{Introduction}

AQPs are a family of transmembrane protein channels featuring six transmembrane helices surrounding a narrow water-permeable channel in which water flows in a single file [1]. In biological membranes, AQPs assemble in tetramers, creating a fifth narrow channel through the center that was suggested to be permeable to $\mathrm{CO}_{2}$ [2]. Thirteen mammalian AQPs have been identified and named AQP0 to AQP12 [3,4]. AQPs structure features an internal tandem repeat of three transmembrane segments and a pair of highly conserved signature asparagine-proline-aspartate (NPA) motifs forming a pore and defining the permeability selectivity $[3,5,6]$.

According to their sequences homologies and permeability, mammalian aquaporins are grossly subdivided into three main groups: (i) orthodox aquaporins (AQP0, AQP1, AQP2, AQP4, AQP5, AQP6, and AQP8), homologues that were initially thought to only allow the passage of water, (ii) aquaglyceroporins (AQP3, AQP7, AQP9, and AQP10), homologues allowing the passage of water, glycerol and some small solutes, and (iii) unorthodox aquaporins (or superaquaporins; AQP11 and AQP12), two AQPs characterized by their divergent evolutionary pathway, and whose channel selectivity is still matter of debate. However, this classification is not exhaustive since additional solutes can pass through, sometimes even more efficiently than the molecules that were initially considered to be the only substrates. AQP3, AQP6, AQP8, and AQP9 are also permeated by ammonia and are also termed ammoniaporins [7]. AQP1, AQP3, AQP5, AQP8, AQP9, and AQP11 also allow the passage of hydrogen peroxide, and are therefore called peroxiporins [8-11]. Moreover, AQP7 and AQP9 have been reported to move arsenite [12], AQP6 to be permeable to nitrate and halide ions $[13,14], A Q P 1$ to be a gated ion channel [15], and AQP9 to facilitate monocarboxylate passage [16]. Some AQP channels have also been reported to facilitate transmembrane movement of gases of biological relevance such as $\mathrm{NO}, \mathrm{CO}_{2}$ or $\mathrm{O}_{2}$ [17-19]. The biological significance of the passage of these other molecules remains largely unknown and object of debate.

In light of their expression in many mammalian tissues and organs, AQPs ensure diverse roles in healthy and pathological conditions $[3,4,20]$. Among the functions ascribed to aquaglyceroporins in the various organs in which they are expressed, important roles are played in liver, adipose tissue and endocrine pancreas where they participate to energy metabolism. By facilitating the uptake/release of glycerol, substrate used for the synthesis of triacylglycerols (TAG) and for gluconeogenesis depending on the states of energy balance, aquaglyceroporins have important implications in the control of fat accumulation in adipose tissue and liver, in glucose homeostasis and oxidative stress [21-25]. In addition, in endocrine pancreas, AQP7-mediated glycerol uptake plays a role in $\beta$-cell insulin secretion [26-28].

This review provides the current state of knowledge concerning the involvement of aquaglyceroporins in energy metabolism by focusing on their expression, role and regulation in liver, adipose tissue and endocrine pancreas. In addition, the review provides an overview of the role of aquaglyceroporins in disorders affecting energy metabolism, the consequences of disorders on aquaglyceroporins expression and function, and the main pharmacological tools available to target aquaglyceroporins.

\section{Structure and characteristics of human aquaglyceroporins}

The overall AQP structure revealed by multiple studies confirmed the existence of the initially suggested "hourglass model" [29]. In accordance with this model, each AQP monomer forms a pore composed of six transmembrane helices connected by five loops (A to E loops; two intracellular and three extracellular). At the vicinity of the extracellular channel mouth, the so-called aromatic/arginine selectivity filter ( $\mathrm{ar} / \mathrm{R} \mathrm{SF}$ ) featuring the most constricted part of the pore controls the passage of molecules based on their size [30]. An arginine residue, highly conserved among AQPs and charged positively, is located in a typically aromatic sidechain environment excluding the passage of protons while accommodating the passage of glycerol and urea [31,32]. Underneath, two highly conserved NPA motifs present in the B and E loops and halfhelices contribute to the formation of the pore center and ensure the exclusion of charged solutes [5,33-37]. Aquaglyceroporins contain two additional peptide spans located within the second and third extracellular loops as compared to orthodox AQPs, and two relatively conserved NPA motifs in which the presence of an aspartic acid (D) in the second NPA motif expands the pore to allow the passage of larger solutes such as glycerol [38,39]. Aquaglyceroporins features an ar/R SF region wider that other AQPs, allowing the passage of larger solutes [40]. Recent studies have confirmed that AQPs pore size determines exclusion properties but not solute selectivity [41]. Despite groundbreaking studies on AQPs structure and better structural insights into AQPs selectivity [1], structural information concerning aquaglyceroporins remains quite limited mainly in reason of to the absence of crystallized proteins.

\section{1. $A Q P 3$}

To our knowledge, the human AQP3 protein crystal structure has not been obtained. However, structural studies have been 
conducted using a homology model of tetrameric AQP3 built based on the crystal structure of the glycerol uptake facilitator protein (GlpF) from Escherichia coli [38,42-44]. Xenopus laevis oocytes and cells expressing AQP3 and atomistic modelling and large-scale simulations have established the permeability of AQP3 to water, glycerol, urea and $\mathrm{H}_{2} \mathrm{O}_{2}$ [45-52]. AQP3 permeability to urea has been the subject of some controversies [53], but recent data indicate the lack of urea permeability of human AQP3 expressed in HEK293 cells [41]. A more recent study revealed the mechanisms of AQP3 water and glycerol permeation at the atomistic level using metadynamic approaches [35]. Both single-file water and glycerol permeate human AQP3 in a bidirectional way in the absence of osmotic gradient, with free energy for permeation smaller for water than for glycerol [35]. The bidirectional water flux is disrupted consequently to glycerol molecules permeating the pore [35]. Although ar/R SF being the narrowest part of the pore, the NPA represents an energy barrier for both water and glycerol permeation [35]. Water and glycerol make hydrogen bonds with amino acids located within the ar/R SF (Y212, A213 and R218), the NPA (N83, N215) and the cytoplasmic pocket (H81, E191) [35]. Human AQP3 point mutation Y212A affected glycerol but not urea permeability, while combined point mutations G203H/Y212A abolished both glycerol and urea permeabilities, and point mutation G203H reduced protein expression [41].

\section{2. $A Q P 7$}

The AQP7 sequence has the particularity to contain conserved NPA motifs modified to NAA (in positions 94-96) and NPS (in positions 226-228) for the first and second motifs, respectively [54,55]. Xenopus laevis oocytes or cells expressing rat, mouse or human AQP7 permeate water, as well as glycerol, urea and $\mathrm{H}_{2} \mathrm{O}_{2}$ $[50,56,57]$. Compared to orthodox AQPs, AQP7 displays lower water permeability in cell-based assays $[58,59]$ but similar water permeability in proteopolymersome assay performed using a glycerol-free set up [60], or reduced water permeability in the presence of glycerol using molecular dynamics simulations [61]. The AQP7 structure has been elucidated in recent works using X-ray crystallography and molecular-dynamics stimulations [57,61]. Human AQP7 displays a pore of around $3 \AA$ of diameter at the selectivity filter [61] comprising amino acid residues F74, G222, Y223 and R229 [57]. AQP7 tetramers contain two monomers with three molecules of glycerol and two monomers with two molecules of glycerol within the pore [57]. The AQP7 structure is quite flexible as its F74 residue undergoes rapid conformational changes from a closed to an opens state, allowing the passage of glycerol without strong orientation restriction [57], with a partly rotating movement that may serve to break hydrogen bonds and allow its movement along the channel pore [61]. Water molecules pass along glycerol molecules to allow glycerol permeation as both molecules compete for hydrogen-bonding sites in the pore [62]. This competition mechanism along with the rotation of glycerol might facilitate glycerol release [61]. Studies of heterologous expression of human AQP7 in yeast displayed similar glycerol permeability for this aquaglyceroporins at $\mathrm{pH}$ values ranging between 6 and 8 [58,59]. However, at acidic $\mathrm{pH}(\mathrm{pH} 5)$, both glycerol $[58,63]$ and water permeabilities were reduced with no change in pore size [63]. The reduction of glycerol permeability of AQP7 at acidic $\mathrm{pH}$ was suggested to be due to the protonation of Y135 and H165 rather than a true gating mechanism. Furthermore, the presence of some $\mathrm{pH}-$ sensitive amino acids at the monomer-monomer interface of the tetramer suggests that the decreased permeability of AQP7 results from the cooperativity between AQP7's monomers [63].

\section{3. $A Q P 9$}

Human AQP9 has been shown to be permeable to water as well as to glycerol, urea and $\mathrm{H}_{2} \mathrm{O}_{2}[12,41,50,56,64,65]$. Despite the lack of structure for human AQP9, two-dimensional crystallization of rat AQP9 indicates that monomers form a tetrameric structure [39]. A homology model of tetrameric AQP9 built based on the crystal structure of the bacterial glycerol uptake facilitator protein $(\mathrm{GlpF})$ reveals the conserved pore residues (G80, H82, N84, N216, R219 in rat $A Q P 9)$ located at the faces presenting groups involved in formation of hydrogen bonds, predominantly in the center of the channel, while the residues conserved only among all aquaglyceroporins (I60, V68, L172, I196, I200, G208, G212, A214, M215) located within helices 2, 4 and 5 and loop $\mathrm{E}$ all sit in the center of the channel on its hydrophobic portion [39]. In addition, residues forming portion of the channel and conserved among all AQP9 homologues (F64, G81, M91, V176, F180, L209, C213) fall into the hydrophobic face of the pore and are located within helices 2 and 4 , loops B and E, and pore helix HB [39]. Proton-exclusion mechanism likely regulates solute permeation in AQP9 similarly to other AQPs as the constricted region of the pore in all AQP9 is conserved similarly to AQPs [39]. Large solute permeation across AQP9 may require solute-induced change in the pore region [39].

\section{4. $A Q P 10$}

Human AQP10 expressed in HEK293 cells exhibit some permeability to glycerol and urea [41], while permeability to $\mathrm{H}_{2} \mathrm{O}_{2}$ remains to be determined. The relatively recent crystal structure determination of AQP10 unveiled its unique characteristic to be stimulated by $\mathrm{pH}$ reduction as it displays a $\mathrm{pH}$-dependent glycerolspecific gating at the intracellular interface, in contrast to other AQPs [60].

In-depth unveiling of the aquaglyceroporins structure contributes to better understanding of diseases and provides additional perspectives for the design of new therapeutic tools.

\section{Hepatic aquaglyceroporins}

Once imported into hepatocytes glycerol is phosphorylated leading to glycerol-3-phosphate (G3P), an essential metabolite in fat accumulation being required for TAG synthesis and gluconeogenesis occurring during fasting or exercise thereby being of critical importance for glucose homeostasis [66]. Glycerol derived from the diet, lipolysis or reabsorbed at the proximal renal tubules contributes to blood free glycerol levels. Furthermore, cell glycerol content results from the conversion of G3P arising from glycolysis, or the conversion of pyruvate, lactate and alanine through a pathway called glyceroneogenesis that occurs in the white and brown adipose tissues, and in the liver to sustain TAG synthesis, especially when TAG metabolism is augmented [66].

Liver exerts a central function in glycerol metabolism, considering its predominant (70-90\%) contribution to the whole-body glycerol metabolism [66]. The use of hepatic glycerol implies sexual dimorphism. Indeed, glucose metabolism and lipid metabolism predominate in men and women, respectively. Under physiological conditions, glycerol metabolism is gender-dependent, especially during hypoglycemia, fasting or exercise [67] (see section 3.1). The 
Table 1

Localization and suggested roles of hepatic aquaglyceroporins.

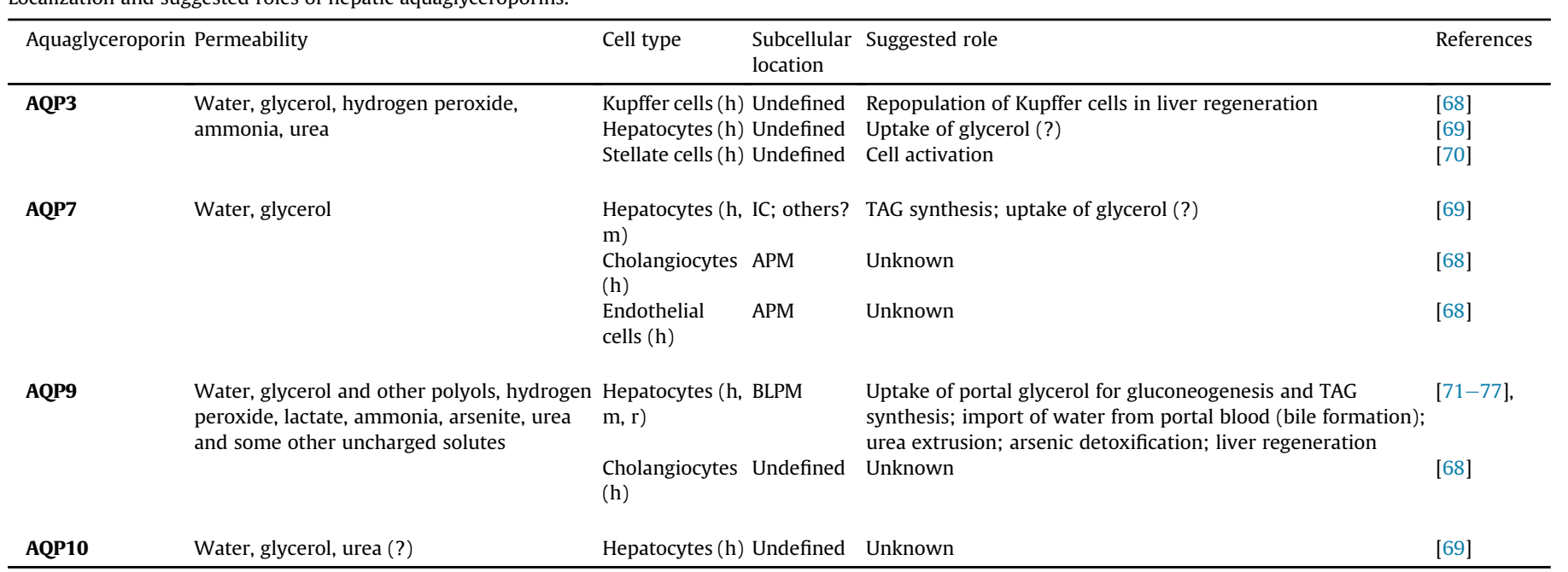

APM, apical plasma membrane; BLPM, basolateral plasma membrane; h, human; IC, intracellular; m, mouse.

liver express all four aquaglyceroporins with difference in term of levels and cellular and subcellular localization. Among these aquaglyceroporins, AQP9 is the most abundantly expressed. Table 1 summarizes some characteristics of liver aquaglyceroporins.

\subsection{Expression in human and rodents}

AQP9 is located at the sinusoidal plasma membrane of rodent and human hepatocytes [71,78]. In rat liver, the AQP9 expression is stronger in the pericentrolobular region of the hepatic lobule than in the periportal area [73,79]. Males exhibit higher hepatic expression of AQP9 than females both in rodents and human $[22,80,81]$.

At a lesser extent compared to AQP9, human hepatocytes also express the other three aquaglyceroporins, AQP3, AQP7, and AQP10 $[68,69]$. Hepatic transcript levels of AQP3 are higher in women than men whereas no sexual dimorphism in the liver transcriptional levels has been observed regarding AQP7 and AQP10 [69]. AQP3 is also reported in human hepatic stellate cells (HSC) [82] and in human Kupffer cells [68].

\subsection{Function}

\subsubsection{AQP9}

AQP9 is the main pathway through which glycerol is imported from portal blood [72,83], a not insignificant aspect given that the glycerol passage through the membrane limits the rate of glycerol use by the liver [84]. Once imported into the cell, glycerol is promptly converted into G3P by the glycerol kinase. G3P is of particular importance as substrate for de novo synthesis of glucose (gluconeogenesis) during short term starvation [85] and for TAG synthesis during feeding [75]. As expected, liver glycerol permeability is reduced in Aqp9-depleted (Aqp $9^{-1-}$ ) mice, while plasma glycerol and TAG levels are increased $[73,83]$. Likely due to its broad selectivity, additional roles for AQP9 in the liver have been suggested in primary bile formation $[74,86]$ and hepatic extrusion of catabolic urea [76]. In liver, AQP9 also mediates excretion of arsenic [77]. AQP9 has also been immunodetected in the cholangiocytes lining mouse intrahepatic bile ducts [68], but the related physiological meaning is still elusive.

\subsection{2. $A Q P 3, A Q P 7$ and $A Q P 10$}

The functional role of AQP3, AQP7, and AQP10 in human hepatocytes, if any, remains to be proven. A role for AQP3 in lipogenesis of quiescent HSC was suggested after finding that its expression decreases during cell activation [70,82]. In human Kupffer cells, AQP3 has been reported to be involved processes occurring during liver regeneration liver diseases (such as cell repopulation, migration, cytokine secretion) [68]. Overall, the roles of AQP3, AQP7, and AQP10 in liver remain to be assessed by additional studies.

\subsection{Regulation}

In rodents, hepatocyte Aqp9 is transcriptionally downregulated by insulin [87], explaining why rodent models of type 1 diabetes [88] and subjects with insulin resistance [69] show increased hepatic levels of AQP9 as well as the diminished glycemia (-10-40\%) of obese diabetic leptin receptor-deficient $\mathrm{db} / \mathrm{db}$ mice lacking Aqp9 [73]. The hepatic glucose metabolism has been modelized as multiple steps integrating the hepatocyte uptake and handling of glycerol in the glucose-insulin axis as a function of the glycogen stores, plasma glycerol and glycerol permeability to hepatic AQP9 protein levels [89]. The model can assess the contribution of AQP9 to murine liver glycerol permeability over time during the course metabolic status [89]. Hepatocyte AQP9 is also regulated transcriptionally by leptin [22,75]. Unexpectedly, leptin and insulin regulate AQP9 transcription differently in rodents and humans $[22,90]$. In the human hepatocellular carcinoma cell line HepG2, insulin and leptin were seen to increase and decrease the expression of AQP9. This was reported to occur through the activation of the phosphatidylinositol 3-kinase/protein kinase $\mathrm{B} /$ mammalian target of rapamycin (PI3K/Akt/mTOR) signaling cascade [75] and AMP protein kinase (AMPK), via forkhead box a2 (Fox a2) [91,92]. However, the question regarding the insulin and leptin regulation of hepatocyte AQP9 in human remains open and needs further investigation since no AQP9 expression was found in a recent work using HepG2 cells [78]. Fasting-induced increase of AQP9 in rat liver was found to be 2.6 times higher in males than females, in line with the concurrent observation that during fasting, male rats showed unmodified plasma glycerol level whereas the plasma glycerol levels were increased in the female counterpart [93], and with the liver glycerol permeability that was higher in males. Ovariectomized rats behave similarly to male rats. These in vivo findings and 
the in vitro data obtained on hepatocytes treated with estrogen infer that sexual dimorphism account for differential AQP9 regulation during fasting and concomitant higher plasma glycerol levels in female [93]. The peroxisome proliferator-activated receptor $\alpha$ (PPAR $\alpha$ ) downregulated AQP9 in rat male periportal hepatocytes [94].

Scarce is the knowledge about the regulation of AQP3, AQP7 and AQP10 in the healthy liver. In HepG2 hepatocytes, AQP3 and AQP7 were found to be upregulated and downregulated, respectively, by leptin [75].

\subsection{Metabolic disorders}

Due to their role in mediating the membrane passage of glycerol, liver aquaglyceroporins, especially AQP9, are of pathophysiological relevance in liver metabolic disorders (Table 2). Seen their peroxiporin activity, roles for $\mathrm{AQP9}$ and $\mathrm{AQP} 3$ cannot be ruled out in disorders of the redox balance and inflammatory diseases.

Non-alcoholic fatty liver disease (NAFLD) is a complex disease characterized by ectopic accumulation of TAG in hepatocytes which varies from simple fatty liver to non-alcoholic steatohepatitis (NASH) and to cirrhosis [100]. NAFLD is frequently associated with the metabolic syndrome often accompanied by obesity and diabetes mellitus with insulin resistance. Involvement of hepatocyte AQP9 has been reported in human NAFLD as well as in studies using rodent or cell models of NAFLD [69,95-97,99]. The decreased AQP9 expression seen in obesity and/or diabetes could contribute to decreasing the substrate availability for de novo TAG synthesis and limiting fat overaccumulation in hepatocytes and to reducing gluconeogenesis to hamper the aggravation of hyperglycemia $[22,69,97]$. Despite comparable levels of liver AQP9 expression, obese women diverged from obese men by their lower liver glycerol permeability [69]. This may reflect the lower incidence of insulin resistance and NAFLD in women than men. However, no relationship was found between hepatic AQP9 expression and extent of liver steatosis in patients with morbid obesity [101]. Also, Aqp9 knockdown in $\mathrm{db} / \mathrm{db}$ mice did not change the hepatic fat content [102]. These results are not consistent with a study using a cell model of NAFLD where silencing of AQP9 prevented or alleviated the degree of intracellular steatosis [103]. A work with male and female mice fed for 24 weeks with a high-fat diet showed that only males displayed liver steatosis without significant modification in AQP9 expression [81]. The originating factors and onset of the fatty liver disease, pathogenic pattern and gender of the studies subjects and animals should be take into account to appreciate the involvement of AQP9 in the disease. Further work is needed to precisely determine the etiopathological implication and modulation of AQP9 in fatty liver disease. Liver AQP9 represents an interesting potential drug target for therapeutic intervention in NAFLD and NASH [24,104]. Although AQP9 did not appear very relevant in hepatic steatosis of alcoholic origin, modification in AQP9-induced glycerol permeability in response to the binding of acetaldehyde, produced by the oxidation of ethanol by alcohol dehydrogenase, to the hepatocyte plasma membrane [105].

Estrogen treatment was found to protect mice against ovariectomy-induced hepatic steatosis by increasing the expression of hepatocyte AQP7. Therefore, AQP7 could become a therapeutic HSCtarget for the prevention or treatment of liver steatosis in postmenopausal women [106].

PNPLA3 (adiponutrin) I148 M variant has been associated with NAFLD, NASH, fibrosis and cancer [70]. AQP3 was found to be strongly reduced in human HSC carrying the PNPLA3 I148 M polymorphism paralleling the decrease in PPAR $\gamma$ activation, which could be rescued by the PPAR $\gamma$ agonist rosiglitazone and the inhibition of JNK. This observation leads to the idea that targeting AQP3 within HSCs activation may be a strategy to treat liver fibrosis in PNPLA3 I148 M patients.

\section{Adipocyte aquaglyceroporins}

Aquaglyceroporins play important roles in the physiology of energy metabolism in adipose tissue. Indeed, upon feeding, glycerol enters the adipocytes and participate to the synthesis of TAG, while upon fasting glycerol exits to the bloodstream upon lipolysis activation. It is therefore no surprise that aquaglyceroporins have been the center of special attention in adipocytes. This review provides a concise and explicit overview of the various facets of aquaglyceroporins in adipocytic glycerol metabolism. Additional information on the subject can be found in previous reviews on the subject (see Refs. [23,24,107-112].

\subsection{Expression}

\subsubsection{Human expression}

Human adipocytes express AQP7 [55,113] and both Aqp7 mRNA and protein levels are upregulated upon differentiation of human preadipocytes into adipocytes [114]. Some controversy exists concerning the location of AQP7 to endothelial cells surrounding adipocytes only [93], or also to adipocytes [115]. The expression of AQP3 [75], AQP9 [75] and AQP10 [115] in human adipocytes has not reached a shared consensus. Indeed, some studies could not detect the expression of both AQP3 and AQP9 [114] or could only detect AQP9 [78]. Worth notifying that AQP11, an unorthodox homologue allowing the passage of glycerol, is also expressed in human fat cells

Table 2

Suggested pathophysiological roles of liver aquaglyceroporins in energy balance disorders.

\begin{tabular}{|c|c|c|c|}
\hline Aquaglyceroporin & Cell type & Pathophysiological involvement & References \\
\hline AQP3 & $\begin{array}{l}\text { Kupffer cells }(\mathrm{h}) \\
\text { Hepatocytes }(\mathrm{h}) \\
\text { Stellate cells }(\mathrm{h})\end{array}$ & $\begin{array}{l}\text { Cell migration and secretion of pro-inflammatory cytokines } \\
\text { Insulin resistance (?) } \\
\text { NAFLD, NASH, fibrosis and cancer (PNPLA3 I148 M variant) }\end{array}$ & $\begin{array}{l}{[68]} \\
{[75]} \\
{[70]}\end{array}$ \\
\hline AQP7 & $\begin{array}{l}\text { Hepatocytes }(h, m) \\
\text { Cholangiocytes }(h) \\
\text { Endothelial cells }(h)\end{array}$ & $\begin{array}{l}\text { Insulin resistance } \\
\text { Unknown } \\
\text { Unknown }\end{array}$ & [75] \\
\hline AQP9 & $\begin{array}{l}\text { Hepatocytes }(\mathrm{h}, \mathrm{m}, \mathrm{r}) \\
\text { Cholangiocytes }(\mathrm{h})\end{array}$ & $\begin{array}{l}\text { NAFLD; NASH; obesity; T2D; hepatocellular carcinoma } \\
\text { Unknown }\end{array}$ & {$[22,69,95-99]$} \\
\hline AQP10 & Hepatocytes (h) & Unknown & \\
\hline
\end{tabular}

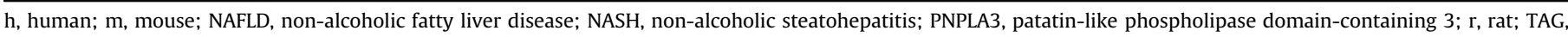
triacylglycerols; T2D, type 2 diabetes mellitus. 
$[116,117]$.

\subsubsection{Mouse expression}

Mouse adipocytes express AQP7 [55,118] but appear to lack AQP3 and AQP9 expression [119,120]. As in human, the expression of AQP7 has been located in endothelial cells surrounding adipocytes only [121], or also in adipocytes [122]. Upon differentiation of 3T3-L1 cells into adipocytes, both Aqp7 mRNA and protein levels are upregulated [122-126], while only AQP3 and AQP9 protein levels are upregulated [124-126]. In some cases, AQP3 and AQP9 expression could not be detected in adipocytes differentiated from 3T3-L1 cells [119].

In addition, AQP11 is expressed in mouse adipocytes [116,125]. AQP10 expression is irrelevant in mouse as it is a nonfunctional pseudogene in that species [127].

Beige and white adipocytes differentiated from 3T3-L1 cells display Aqp7, Aqp3 and Aqp9 mRNA levels, while only AQP9 protein levels were detected [128]. Time-course analysis of aquaglyceroporins mRNA levels during the differentiation process revealed significant increase in Aqp7 and AQP9 mRNA levels during the differentiation into white adipocyte [128].

\subsubsection{Rat expression}

Rat adipocytes express AQP3, AQP7, and AQP9, while the expression of AQP10 has not been reported [69,129].

\subsection{Regulation}

\subsubsection{Trafficking mechanism}

Protein trafficking plays a key role in the regulation of aquaglyceroporins function. Indeed, aquaglyceroporins localized in subcellular vesicles translocated to the plasma membrane (to ensure transcellular glycerol passage) upon stimulation with insulin and hormones inducing the activation of cAMP signaling pathway [75,115,122,130,131].

cAMP-inducing hormones or agents induced translocation of AQP3, AQP7 and AQP10 from intracellular vesicles to the plasma membrane, but had no effect on AQP9 localized at the membrane [75,115]. Upon insulin stimulation of 3T3-L1 adipocytes, AQP3 and AQP7 tended to appear more prominently surrounding the lipid droplets and while AQP9 localization increased at the plasma membrane [75].

\subsubsection{Transcriptional mechanism}

The transcription of aquaglyceroporins is regulated by hormones (i.e, insulin, catecholamines, steroids) and inflammatory mediators (i.e, TNF $\alpha$ and lipopolyssacharides) [75,113,118,125,132]. Both human and mouse Aqp7 transcription is upregulated by peroxisome proliferator-activated receptor gamma (PPAR $\gamma$ ) $[118,133]$ and modulated by the Küppel-like factor 15 (KLF-15), a transcription factor playing a role in lipogenesis [134].

\subsubsection{Epigenetic mechanism}

DNA methylation at GpG dinucleotides, one of the epigenetic mechanisms by which cells modulate gene expression, can regulate Aqp7 expression [135]. The presence of high proportion of methylated GpG-sites in Aqp7 gene promoter correlated with a downregulation of the gene expression [136]. While some miRNAs can interact with some aquaglyceroporins, their role in aquaglyceroporins regulation in adipose tissue remains to be investigated [137,138]. Further analyses will be required to shed more light on the role of epigenetic mechanisms in aquaglyceroporins regulation in adipose tissue.

\subsection{4. $\mathrm{pH}$-induced mechanism}

So far, all aquaglyceroporins, with the exception of AQP9, have been reported to be regulated by a $\mathrm{pH}$-dependent gating mechanism.

Indeed, rat AQP3 glycerol passage was significantly lower at $\mathrm{pH}$ 6.0 and completely abolished at $\mathrm{pH}$ below 5.7 [47,139], while another study showed it was unmodified at $\mathrm{pH}$ in the range 6-7 [140]. Extracellular pH reduction also decreased AQP3 water permeability, involving H53, Y124 and H154 residues [141]. The investigation of the molecular mechanisms responsible for $\mathrm{pH}$ dependent AQP3 gating disclosed important structural features [139].

Human AQP7 displayed similar glycerol permeability at both high and low $\mathrm{pH}$ ( $\mathrm{pH}$ range $6-8$ ) $[58,59]$. In contrast, at $\mathrm{pH} 5$, that may not be quite meaningful physiologically, glycerol $[58,63]$ and water permeabilities are reduced, but not the pore size [63]. The reduction in glycerol permeability of AQP7 may be consecutive to the protonation of Y135 and H165 rather than a true gating mechanism. In addition, the protonated residues may be responsible for a cooperativity change between the AQP7 monomers within the tetramer that alters permeability [63].

Human AQP10 displays a pH-dependent glycerol-specific gating at the intracellular interface, in contrast to other AQPs [60]. Upon double protonation induced by low $\mathrm{pH}$ exposure, the amino acid $\mathrm{H} 80$ played a critical role in the regulation as it acted as the $\mathrm{pH}$ sensor propagating conformational changes leading to the opening of AQP10 [60]. Indeed, upon H80 protonation, H80 reorients and stabilizes with E27 prior to leading to a structural shift of F85 and the rearrangement of the loop (containing V76-S77) in conjunction with R94 to allow the passage of glycerol [60].

\subsubsection{Phosphorylation mechanism}

Current knowledge about phosphorylation of aquaglyceroporins is very limited. Indeed, only human AQP3 was shown to be phosphorylated upon cAMP-induced hormone on T514 and this phosphorylation paralleled the increase in AQP3 trafficking to the plasma membrane in an intestinal epithelial cell line [142]. It remains to be determined whether other aquaglyceroporins can undergo phosphorylation upon hormone stimulation in parallel with their trafficking.

\subsection{Function}

Adipose tissue ensures the synthesis and storage of TAG during feeding, and their degradation and release during fasting [66,143]. These processes require transmembrane passage of glycerol through aquaglyceroporins. As such, aquaglyceroporins participate to energy metabolism. The function of aquaglyceroporins has been deciphered using aquaglyceroporin knockout animals, adipocyte differentiation models, and adipose tissue samples. The role played by AQP7 in adipocytic glycerol release has been unveiled using differentiated adipocytes [119] and Aqp7 knockout mice $[120,144,145]$. In addition, AQP3 could contribute to cell glycerol exit during lipolysis, and AQP9 could allow cell glycerol entrance during TAG synthesis [75]. The involvement of AQP9 in adipocyte glycerol uptake relies on various facts. AQP9 expression located at the plasma membrane of mouse 3T3-L1 adipocytes, and was higher upon insulin stimulation [75]. Insulin increased AQP9, in addition to AQP3 and AQP7, in human omental adipocytes, while leptin decreased AQP9, as well as AQP7, expression though the PI3K/Akt/ mTOR pathway [75]. Due to the low activity of the adipose glycerol kinase during lipogenesis, glycerol uptake is likely limited. Using selective AQPs inhibitors, the relative contribution of aquaglyceroporins to the glycerol permeability of 3T3L1 adipocytes were estimated to $68 \%$ for AQP3, 3\% for AQP7 and 12\% for AQP9 
[126]. However, the contribution of AQP7 to glycerol permeability was estimated to $45 \%$ using RNA interference [144]. Plausible explanations may account for the observed variability in AQP7 contribution to adipocytic glycerol permeability. Indeed, incomplete effects of the inhibitors and possible off target effects of RNA interference could respectively underestimate or overestimate AQP7 contribution to adipocytic glycerol permeability [126].

Lower expression and lack of regulation of aquaglyceroporins in beige adipocytes versus white adipocytes differentiated from 3T3L1 cells are in agreement with the commitment of beige adipocytes to metabolize fat to produce heat instead of performing TAG synthesis and degradation that involves glycerol passage [128].

Adipocytes undergo rapid intracellular acidification or alkalinization in response to lipolytic agents or insulin, respectively [146-150]. Therefore, adipocyte intracellular $\mathrm{pH}$ modifications are likely involved in $\mathrm{pH}$-induced gating mechanisms of aquaglyceroporins. Under fasting, lipolysis is known to induce intracellular $\mathrm{pH}$ acidification that does not drop below pH $6.5[60,146]$. Therefore, under these conditions, AQP3 and AQP7 would retain a glycerol permeability superior to 50\% [63], while AQP10 would display high glycerol permeability [60], both contributing to glycerol efflux. In contrast, under feeding, insulin-induced intracellular $\mathrm{pH}$ alkalinization would trigger high AQP3- and AQP7-mediated glycerol permeability contributing to glycerol influx, but low AQP10-mediated glycerol permeability. While it remains to be determined whether AQP9 also undergoes a $\mathrm{pH}$-dependent gating mechanism, AQP9 may be still involved in glycerol import upon feeding (see above).

AQP11 is expressed in the endoplasmic reticulum and its expression is upregulated during human adipocyte differentiation and lipolysis [117]. Physiologically, AQP11 allows glycerol passage for TAG synthesis in nascent lipid droplets in the endoplasmic reticulum [117].

Based on current understanding of the role of aquaglyceroporins in adipocyte energy metabolism, we proposed an updated working model whereby mainly AQP3, AQP7 and AQP10 would be involved in glycerol exit during lipolysis, while mainly AQP3, AQP7 and AQP9 would be involved in glycerol entrance during lipogenesis [126]. However, the contribution of each aquaglyceroporins to glycerol metabolism in adipose tissue remains to be fully deciphered, possibly with the use of mice carrying the conditional knockout of one or more aquaglyceroporin gene(s) or using isoform-specific and potent inhibitors.

\subsection{Metabolic disorders}

A brief overview on the role of adipocytic aquaglyceroporins in metabolic disorders will be provided, due to available extensive review on the subjects $[24,90,107-111]$. Table 3 summarizes the involvement of aquaglyceroporins in metabolic disorders.

The capacity of Aqp7 knockout mice to develop or not an obesity phenotype may arise from their genetic background [144,145,161]. The site of AQP7 expression, exclusively in endothelial cells [93,121] or in endothelial cells and adipocytes [115,122], could account for the susceptibility to develop obesity [162]. In an animal model of metabolic syndrome (i.e. rats depleted in n3-polyunsaturated fatty acids (PUFA), the level of AQP7 protein, but not mRNA, was decreased in adipose tissue (PUFA depletion is likely responsible for the absence of PPAR $\gamma$ activation that is then uncapable to transactivate AQP7 [118] and thereby glycerol passage [158]. Lipopolysaccharide, known to play an important role in obesity [163], decreased glycerol permeability and increased TAG content in 3T3L1 adipocytes, without modification of AQP7 protein expression [126].

Animals fed an obesogenic high fat diet displayed various modulations of Aqp3, Aqp7 and Aqp9 mRNA levels [81,129,164-166]. Data variability may arise from differences in animal species (rat, mouse), adipose tissue investigated, duration of obesogenic diet, animal genetic background and assay conditions.

DNA methylation of the human $A Q P 7$ gene has been associated with adiposity. Indeed, Aqp7 gene methylation was significantly increased in four adiposity phenotypes including android fat mass, android:gynoid fat ratio and trunk:limb fat ratio [135]. Furthermore, high proportion of methylated GpG-sites detected in Aqp7 gene promoter correlated with a downregulation of the gene expression in human hypertrophic white adipose tissue that is generally associated with insulin resistance and type 2 diabetes [136]. However, Aqp7 gene methylation could not be detected in rats fed with high fat diet to create an obesogenic environment [167]. Nevertheless, Aqp7 downregulation, achieved using interfering RNA knockdown of Aqp7, stimulated lipid storage in mesenchymal stem cells subsequently differentiated into adipocytes [136], consistently with the role of AQP7 to ensure the passage of glycerol, used as a substrate and product of lipid metabolism [119].

The human $A Q P 7$ gene is located in a chromosomal region linked to type 2 diabetes (T2D) [133,160] and metabolic syndrome [159]. Therefore, several studies have assessed AQP7 expression in patients with obesity, T2D and metabolic syndrome. However, no correlation has been observed between $A Q P 7$ gene mutations and obesity or T2D [113]. Adipose tissue from obese subjects presents either higher or lower AQP7 expression, according to the studies [75,101,151-157]. Clinical features of obese subjects, as well as their gender, may account for these apparent contradictory data [22]. Lower KLF-15 expression that could reduce $A Q P 7$ expression may account for insulin resistance in adipose tissue [134].

AQP11 has recently been shown to act an endoplasmic reticulum-resident protein involved in endoplasmic reticulum stress induced by lipotoxicity and inflammation in human obesity [117]. The peroxiporin activity of AQP11 appears to lessen the endoplasmic reticulum stress caused by lipotoxicity and inflammation [117].

Table 3

Suggested pathophysiological roles of adipose tissue aquaglyceroporins

\begin{tabular}{|c|c|c|c|}
\hline Aquaglyceroporin & Cell type & Pathophysiological involvement & References \\
\hline \multirow[t]{4}{*}{ AQP7 } & Adipocytes (h, m, r) & Obesity & {$[75,101,114,135,144,145,151-157]$} \\
\hline & Endothelial cells $(\mathrm{h}, \mathrm{m})$ & Metabolic syndrome & {$[158,159]$} \\
\hline & & Insulin resistance & [136] \\
\hline & & $\mathrm{T} 2 \mathrm{D}$ & {$[133,160]$} \\
\hline AQP3 & Adipocytes (h, m, r) & Unknown & \\
\hline AQP9 & Adipocytes (h, m, r) & Unknown & \\
\hline AQP10 & Adipocytes (h) & Unknown & \\
\hline AQP11 & Adipocytes (h, m) & Obesity & [117] \\
\hline
\end{tabular}

h, human; m, mouse; r, rat; T2D, type 2 diabetes mellitus. 
Despite numerous studies aiming at evaluating the role of aquaglyceroporins in energy metabolism disorders, additional studies will be required to deepen our knowledge on the subject.

\section{Pancreatic endocrine aquaglyceroporins}

\subsection{Expression}

Endocrine cell clustered into islets of Langerhans and single endocrine cells scattered among the pancreas constitutes the endocrine pancreas. The islets of Langerhans are clusters of few to several thousand cells of five main well-characterized endocrine cell types: $\beta$-cells producing insulin; $\alpha$-cells producing glucagon; $\delta$ cells producing growth hormone-inhibiting hormone (GHIH - also termed somatostatin); $\gamma$-cells producing pancreatic polypeptide (PP); and $\varepsilon$-cells producing ghrelin $[168,169]$. Among human and rodent islets of Langerhans, the endocrine cells types vary in their proportions [170-172] and localization (core or rim of islets) [170,171]. From a physiological point of view, both insulin and glucagon play major roles in the control of energy metabolism in post-prandial and in pre-prandial states, respectively. Indeed, it is well known that insulin, secreted in response to increased glycaemia, and glucagon, secreted in response to decreased glycaemia, are anabolic and catabolic hormones, respectively, controlling the mobilization and storage of carbohydrates, lipids and amino acids.

Current state of knowledge reports the expression of AQP7 in rodent (rat and mouse) $\beta$-cells $[26-28,128,161]$. In mouse and rat $\beta$ cells, AQP3 mRNA expression has not been detected [161,173]. While AQP9 mRNA expression has not been detected in mouse $\beta$ cells, its expression was detectable in $10 \%$ of rat pancreatic samples analyzed [173].

The possible presence of additional aquaglyceroporins in $\beta$-cells, as well as aquaglyceroporins expression in other islet endocrine cell types require further investigations.

\subsection{Regulation}

In response to triggered lipolysis in adipocytes, increased blood glycerol levels will induce local $\beta$-cells intracellular glycerol concentration increase and subsequent $\beta$-cell activation. In addition, insulin or other agents downregulating AQP7 expression will likely increase the intracellular $\beta$-cell glycerol concentration and induce cell activation [113,118]. Recent data partly corroborated this hypothesis as Aqp7 overexpression decreased insulin release in rat RIN-m5F $\beta$-cells [128]. However, reduced Aqp7 expression had no impact on insulin release [128]. In addition, tumor necrosis factoralpha (TNF $\alpha$ ) and LPS, respectively decreasing or increasing Aqp7 mRNA expression, both decreased insulin release in rat RIN-m5F $\beta$ cells [128]. This apparent contradiction might be related to the measurement of Aqp7 mRNA levels rather than AQP7 protein expression levels or cell glycerol permeability under TNF $\alpha$ and LPS treatment, to the condition of insulin secretion (in the absence or presence of glycerol), or to the effects of cytokines released upon $\mathrm{TNF} \alpha$ and LPS stimulation. As such, additional experiments will help shedding light on this issue.

\subsection{Function}

The role of AQP7 in $\beta$-cell intracellular glycerol content and both insulin production and secretion has been deciphered using Aqp7knockout (KO) mice [27,121,144,161], ex vivo $\beta$-cells [26] and BRINDDB11 $\beta$-cell line [28]. A reduction in $\beta$-cell number, size and insulin content was documented in Aqp7-KO mice as compared to wild type (WT) mice [161]. In addition, Aqp7-KO mice displayed higher intra-islet levels of both glycerol and TAG, higher glycerol kinase activity, but no glycerol efflux in response to forskolin [161]. Depending on the genetic background of Aqp7-KO mice models used, the animals displayed various phenotypes characterized by either normal glycaemia with underdetermined insulinemia [121], normal glycaemia with hyperinsulinemia [161], or hyperglycaemia and hyperinsulinemia [144]. The various phenotypes of Aqp7-KO mice models could result from combined interactions between AQP7 and other gene products. This hypothesis warrants additional experiments to decipher the AQP7 interactome. Fig. 1 resumes the phenotype of Aqp7-KO mice.

The current model of insulin secretion is based on the existence of sequential mechanisms including: glucose entry through glucose transporter type 2 (GLUT2), glucose metabolization, intracellular ATP level increase, ATP-sensitive potassium channels inhibition, membrane depolarization, voltage-dependent calcium channels opening, intracellular calcium concentration increase, and insulincontaining granules release [174]. Glucose entry in $\beta$-cell leads to cell swelling [175], and subsequent activation of volume-regulated anion (VRAC) channel inducing regulatory volume decrease, cell depolarization, voltage-dependent calcium channel activation, intracellular calcium level increase, and insulin secretion [176,177]. Upon exposure of rat $\beta$-cells or rat BRIN-DB 11 cells to extracellular isosmotic addition of glycerol, cells encounter cell swelling and subsequent here above-mentioned mechanisms leading to insulin release (Fig. 2) [26,28,178]. Both glycerol entry and metabolization are likely accounting for the observed $\beta$-cells activation [26]. Extracellular isosmotic addition of glycerol, extracellular hypotonicity or increased D-glucose level induced increased insulin release in $\beta$-cells from Aqp7-KO mice as compared to WT mice [27]. The role played by glycerol and AQP7 in insulin secretion corroborate the correlation between glucose-induced insulin secretion and $\beta$ cell lipolysis [179-181]. Consequently, AQP7 allows glycerol passage, and modulate the insulin secretion pathway at a distal downstream site [27].

\subsection{Metabolic disorders}

Aquaglyceroporins are described to be of pathophysiological relevance in metabolic disorders affecting the pancreas (Table 4). Indeed, in the context of type 2 diabetes, both insulin resistance and insulinemia may also induce an intracellular glycerol concentration increase in $\beta$-cells [178]. In obesity, $\beta$-cell activation of TNF $\alpha$ receptor and TLR4 may play a role in type 2 diabetes by modulating Aqp7 expression. Indeed, TNF $\alpha$ and LPS, inducing cytokine production/release, respectively decreased or increased Aqp7 mRNA expression in rat RIN-m5F $\beta$-cells [128]. Opposite to lean rats, pancreas from obese rats have by higher AQP7 mRNA and protein levels. In addition, Aqp7 mRNA levels are negatively correlated with total ghrelin and glucagon-like peptide 1 (GLP-1) concentrations [173]. Restored pancreatic AQP7 expression and improved pancreatic $\beta$-cell function have been observed in obese rats with sleeve gastrectomy [173]. AQP7 could become a the target for therapeutic intervention in metabolic diseases, and in particular obesity and diabetes [112].

Overall, additional studies are necessary to further deciphering the function of AQP7 in $\beta$-cells and metabolic diseases, assess the possible presence and role of other aquaglyceroporins, as well as determine the expression of aquaglyceroporins in other islet endocrine cell types.

\section{Main pharmacological tools targeting aquaglyceroporins}

Reflecting the strong interest in the subject, the full characterization of what it is already known and search for new and more selective and potent inhibitors of aquaglyceroporins and, more 


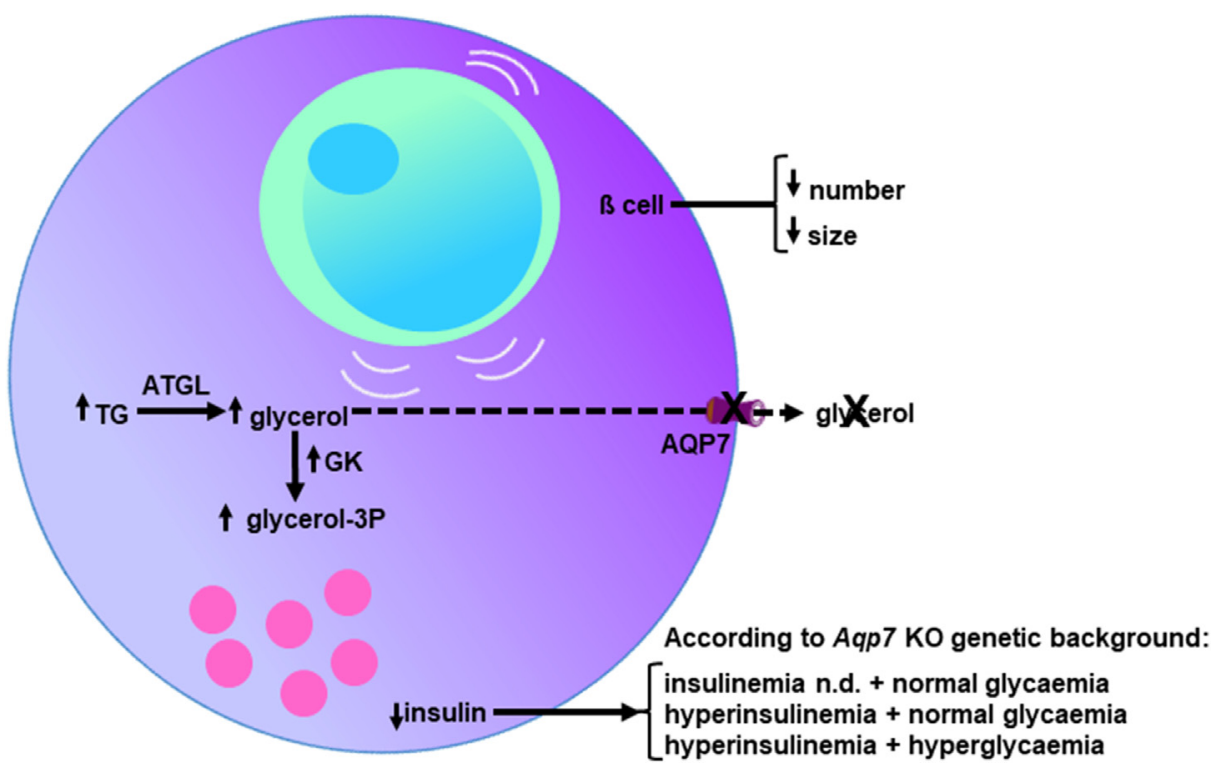

Fig. 1. Characteristics of Aqp7-KO mice. ATGL: adipose triglyceride lipase; GK: glycerol kinase; TAG, triacylglycerols.
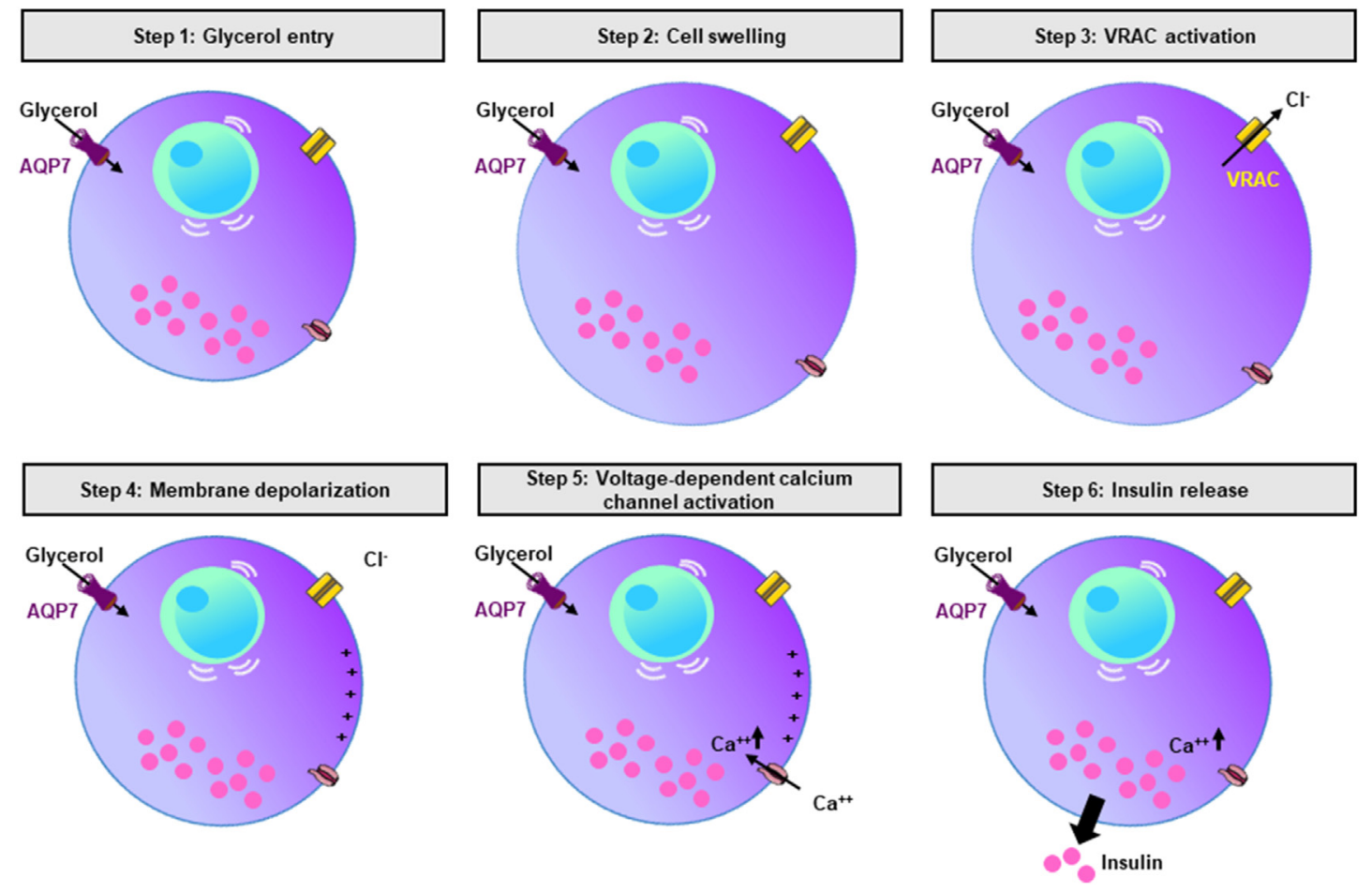

Fig. 2. AQP7 function in $\beta$-cell insulin secretion. Following glycerol entry through AQP7 in $\beta$-cells, multiple steps lead to insulin secretion.

Table 4

Suggested pathophysiological roles of pancreas aquaglyceroporins.

\begin{tabular}{|c|c|c|c|}
\hline Aquaglyceroporin & Cell type & Pathophysiological involvement & References \\
\hline AQP7 & $\beta$-cells $(\mathrm{m}, \mathrm{r})$ & Obesity & {$[112,128,173]$} \\
\hline AQP9 & $\beta$-cells $\left(\mathrm{r}^{\mathrm{a}}\right)$ & $\begin{array}{l}\text { Diabetes } \\
\text { unknown }\end{array}$ & $\begin{array}{l}{[161]} \\
{[173]}\end{array}$ \\
\hline
\end{tabular}

m: mouse: r: rat.

a Present in about $10 \%$ of samples. 
generally, of all aquaporin groups is currently very intense $[24,182,183]$. For the purpose of this review, only aquaglyceroporin inhibitors are considered.

The $\mathrm{Cu}^{2+}$ and $\mathrm{Ni}^{2+}$ ions were reported to bind to extracellular loop sites of human AQP3 [141,184]. In the related studies, inhibitor potency was not fully clarified as it resulted to vary depending on the employed buffer. Indeed, $\mathrm{Cu}^{2+}$ inhibited AQP3 water and glycerol permeability with an $\mathrm{IC}_{50}$ ranging from $\sim 5 \mu \mathrm{M}$ in bicarbonate buffer to the millimolar range in Tricine or HEPES buffers, and had no effect of AQP7 permeabilities in bicarbonate buffer [141,184]. It is worth mentioning that the normal human plasma $\mathrm{Cu}^{2+}$ levels range from 1 to $15 \mu \mathrm{M}$. Nickel chloride $(1 \mathrm{mM}$ ) reduced AQP3 water permeability by about $60 \%$ in human bronchial epithelium cells overexpressing the protein, compared to sham-transfected cells. The inhibitory effect exerted by $\mathrm{Ni}^{2+}$ ions likely occurs on the extracellular loop residues Trp-128, Ser-152, and His-241 [141].

The $\mathrm{Hg}^{2+}$ ion binds to a pore-lining cysteine residue found on most AQPs including AQP3, AQP9 and AQP10 (but not AQP7) and blocks the channel. However, mercury and its compounds are toxic due to their non-specificity causing off-target effects the reason why it is used only in cell-based studies.

Some gold ${ }^{\text {III }}$ compounds have been reported to block the molecular passage operated by aquaglyceroporin channels. The $\mathrm{Au}^{\text {III }}$ based compound $\left[\mathrm{Au}\right.$ (phen) $\left.\mathrm{Cl}_{2}\right] \mathrm{Cl}$ (phen = 1,10-phenanthroline; Auphen) was proved to inhibit AQP3 [185]. Biophysical and computational analyses suggested binding of Auphen to the side chain of a cysteine residue (Cys40) located nearby of the AQP3 pore constriction [43]. Auphen was also reported to inhibit mouse and human AQP7 through direct binding to a methionine (Met47) at the pore mouth facing the intracellular compartment [186]. AQP3 has been shown to be blocked by Aubipy ([Au (bipy) $\left.\mathrm{Cl}_{2}\right]^{+}$(bipy $=2,2^{\prime}-$ bipyridine), another gold coordination compounds [187-189].

Phloretin, a bioactive chalcone with various health benefits [184], is a proven blocker of the facilitated passage of glycerol and urea across membranes [49,190]. Although it does not allow to distinguish among the various aquaglyceroporins phloretin is largely employed in the biophysical characterization of the aquaglyceroporin-mediated passage of glycerol and urea in basic research $[76,83]$. Small molecule inhibitors of AQP9 were identified after screening a commercially available library of drug-like molecules [72,191]. One of the identified inhibitors, the heterocyclic compound HTS13286, inhibited the AQP9-mediated glycerol permeation with an $\mathrm{IC}_{50}$ of $\sim 2 \mu \mathrm{M}$. The limited solubility in water $(\sim 25 \mu \mathrm{M}$ in $1 \%$ DMSO-containing aqueous solution) makes HTS13286 not suitable for in vivo applications. However, HTS13286 is revealing a good blocker of AQP9 for characterizing the biophysical properties and function in vitro not to mention the possibility of identifying structural derivatives with a more potent inhibitory action on AQP9 and/or with higher water solubility for potential drug development.

Novel inhibitors of AQP3 and AQP7 have recently been identified [50]. The heterocyclic compounds DFP00173 and Z433927330 blocked the glycerol permeability of human erythrocytes with an IC $_{50}$ of $~ 0.2 \mu \mathrm{M}$ and $\sim 0.6 \mu \mathrm{M}$, respectively. In CHO cells, compound DFP00173 specifically blocked mouse AQP3 with an $\mathrm{IC}_{50}$ of $\sim 0.1 \mu \mathrm{M}$ but not AQP7 and AQP9, while Z433927330 inhibited mouse AQP7 with an IC $_{50}$ of $\sim 0.2 \mu \mathrm{M}$ but not AQP3 and AQP9. The IC 50 values for Z433927330 for mouse AQP3 and AQP9 were $\sim 0.7 \mu \mathrm{M}$ and $\sim 1.1 \mu \mathrm{M}$, respectively. In the same study by Sonntag and coworkers, the previously identified AQP9 inhibitor RF03176 [72] was found to block aquaglyceroporin $\mathrm{H}_{2} \mathrm{O}_{2}$ permeability. Molecular docking suggested binding of Z433927330, DFP00173 and RF03176 to amino acid residues at the cytoplasmic entrance of the AQP9 pore.

\section{Conclusions and outlook}

Adipose, liver and endocrine pancreas aquaglyceroporins play a significant role in the function these organs exert in metabolic and energy homeostasis. In the light of their physiological functions, aquaglyceroporins play relevant roles in diseases accompanied by metabolic and energy imbalances. Modulation of aquaglyceroporins by some bioactive phytocompounds is found to prevent or improve some chronic metabolic disease. New and more sustainable aquaglyceroporins inhibitors are being discovered offering promise for novel therapeutic strategies where targeting aquaglyceroporins may help managing obesity, diabetes and NAFLD/NASH. Additional and important achievements on the role and regulation of aquaglyceroporins in health and disease as well as their translational value are anticipated.

\section{Declaration of competing interest}

The authors declare that they have no known competing financial interests or personal relationships that could have appeared to influence the work reported in this paper.

\section{Acknowledgments}

This study was supported by grants from the Fonds David and Alice Van Buuren, Jaumotte Demoulin Foundation, de Meurs François Foundation and Defay Fund (Université Libre de Bruxelles) to C.D. Financial support to G.C. from Italian "Programmi di Ricerca Scientifica di Rilevante Interesse Nazionale 2017” (PRIN2017; grant \# 2017J92TM5) is gratefully acknowledged. The Authors thank Bahija Jellouli for her secretarial help.

\section{References}

[1] S. Kreida, S. Törnroth-Horsefield, Structural insights into aquaporin selectivity and regulation, Curr. Opin. Struct. Biol. 33 (2015) 126-134, https:// doi.org/10.1016/j.sbi.2015.08.004.

[2] R. Kaldenhoff, L. Kai, N. Uehlein, Aquaporins and membrane diffusion of $\mathrm{CO} 2$ in living organisms, Biochim. Biophys. Acta 1840 (2014) 1592-1595, https:// doi.org/10.1016/j.bbagen.2013.09.037.

[3] P. Agre, Aquaporin water channels (nobel lecture), Angew. Chem., Int. Ed. Engl. 43 (2004) 4278-4290, https://doi.org/10.1002/anie.200460804.

[4] A.S. Verkman, Novel roles of aquaporins revealed by phenotype Analysis of knockout mice, Rev. Physiol. Biochem. Pharmacol. 155 (2005) 31-55, https:// doi.org/10.1007/s10254-005-0040-1.

[5] K. Ishibashi, Y. Morishita, Y. Tanaka, The evolutionary aspects of aquaporin family, Adv. Exp. Med. Biol. 969 (2017) 35-50, https://doi.org/10.1007/97894-024-1057-0_2.

[6] M. Kourghi, J.V. Pei, M.L. De Ieso, S. Nourmohammadi, P.H. Chow, A.J. Yool, Fundamental structural and functional properties of aquaporin ion channels found across the kingdoms of life, Clin. Exp. Pharmacol. Physiol. 45 (2018) 401-409, https://doi.org/10.1111/1440-1681.12900.

[7] T.P. Jahn, A.L.B. Møller, T. Zeuthen, L.M. Holm, D.A. Klaerke, B. Mohsin, W. Kühlbrandt, J.K. Schjoerring, Aquaporin homologues in plants and mammals transport ammonia, FEBS Lett. 574 (2004) 31-36, https://doi.org/ 10.1016/j.febslet.2004.08.004.

[8] G.P. Bienert, A.L.B. Møller, K.A. Kristiansen, A. Schulz, I.M. Møller J.K. Schjoerring, T.P. Jahn, Specific aquaporins facilitate the diffusion of hydrogen peroxide across membranes, J. Biol. Chem. 282 (2007) 1183-1192, https://doi.org/10.1074/jbc.M603761200.

[9] R.A. Marinelli, M.J. Marchissio, Mitochondrial aquaporin-8: a functional peroxiporin? Antioxidants Redox Signal. 19 (2013) 896, https://doi.org/ 10.1089/ars.2013.5505.

[10] M. Bertolotti, S. Bestetti, J.M. García-Manteiga, I. Medraño-Fernandez, A. Dal Mas, M.L. Malosio, R. Sitia, Tyrosine kinase signal modulation: a matter of H2O2 membrane permeability? Antioxidants Redox Signal. 19 (2013) 1447-1451, https://doi.org/10.1089/ars.2013.5330.

[11] H. Sies, Role of metabolic $\mathrm{H} 2 \mathrm{O} 2$ generation: redox signaling and oxidative stress, J. Biol. Chem. 289 (2014) 8735-8741, https://doi.org/10.1074/ jbc.R113.544635.

[12] R. Mukhopadhyay, H. Bhattacharjee, B.P. Rosen, Aquaglyceroporins: generalized metalloid channels, Biochim. Biophys. Acta 1840 (2014) 1583-1591, https://doi.org/10.1016/j.bbagen.2013.11.021.

[13] M. Yasui, A. Hazama, T.H. Kwon, S. Nielsen, W.B. Guggino, P. Agre, Rapid 
gating and anion permeability of an intracellular aquaporin, Nature 402 (1999) 184-187, https://doi.org/10.1038/46045.

[14] M.P.H. Yasui, Regulated anion permeability of aquaporin-6, Handb. Exp. Pharmacol. (2009) 299-308, https://doi.org/10.1007/978-3-540-79885-9_ 15.

[15] A.J. Yool, E.M. Campbell, Structure, function and translational relevance of aquaporin dual water and ion channels, Mol. Aspect. Med. 33 (2012) 553-561, https://doi.org/10.1016/j.mam.2012.02.001.

[16] H. Tsukaguchi, S. Weremowicz, C.C. Morton, M.A. Hediger, Functional and molecular characterization of the human neutral solute channel aquaporin9, Am. J. Physiol. 277 (1999) F685-F696, https://doi.org/10.1152/ ajprenal.1999.277.5.F685.

[17] N.L. Nakhoul, B.A. Davis, M.F. Romero, W.F. Boron, Effect of expressing the water channel aquaporin- 1 on the $\mathrm{CO} 2$ permeability of Xenopus oocytes, Am. J. Physiol. 274 (1998) C543-C548, https://doi.org/10.1152/ ajpcell.1998.274.2.C543.

[18] M. Herrera, N.J. Hong, J.L. Garvin, Aquaporin-1 transports NO across cell membranes, Hypertension 48 (2006) 157-164, https://doi.org/10.1161/ 01.HYP.0000223652.29338.77.

[19] Y. Wang, E. Tajkhorshid, Molecular mechanisms of conduction and selectivity in aquaporin water channels, J. Nutr. 137 (2007) 1509S-1515S, discussion 1516S-1517S.

[20] R.E. Day, P. Kitchen, D.S. Owen, C. Bland, L. Marshall, A.C. Conner, R.M. Bill, M.T. Conner, Human aquaporins: regulators of transcellular water flow, Biochim. Biophys. Acta 1840 (2014) 1492-1506, https://doi.org/10.1016/ j.bbagen.2013.09.033.

[21] I.V. da Silva, J.S. Rodrigues, I. Rebelo, J.P.G. Miranda, G. Soveral, Revisiting the metabolic syndrome: the emerging role of aquaglyceroporins, Cell. Mol. Life Sci. 75 (2018) 1973-1988, https://doi.org/10.1007/s00018-018-2781-4.

[22] A. Rodríguez, R.A. Marinelli, A. Tesse, G. Frühbeck, G. Calamita, Sexual dimorphism of adipose and hepatic aquaglyceroporins in health and metabolic disorders, Front. Endocrinol. 6 (2015) 171, https://doi.org/10.3389/ fendo.2015.00171.

[23] I.V. da Silva, J.S. Rodrigues, I. Rebelo, J.P.G. Miranda, G. Soveral, Revisiting the metabolic syndrome: the emerging role of aquaglyceroporins, Cell. Mol. Life Sci. 75 (2018) 1973-1988, https://doi.org/10.1007/s00018-018-2781-4.

[24] G. Calamita, J. Perret, C. Delporte, Aquaglyceroporins: drug targets for metabolic diseases? Front. Physiol. 9 (2018) 851, https://doi.org/10.3389/ fphys.2018.00851.

[25] G. Tamma, G. Valenti, E. Grossini, S. Donnini, A. Marino, R.A. Marinelli, G. Calamita, Aquaporin membrane channels in oxidative stress, cell signaling, and aging: recent advances and research trends, Oxid Med Cell Longev 2018 (2018) 1501847, https://doi.org/10.1155/2018/1501847.

[26] L. Best, P.D. Brown, A.P. Yates, J. Perret, M. Virreira, R. Beauwens, W.J. Malaisse, A. Sener, C. Delporte, Contrasting effects of glycerol and urea transport on rat pancreatic beta-cell function, Cell. Physiol. Biochem. 23 (2009) 255-264, https://doi.org/10.1159/000218172.

[27] K. Louchami, L. Best, P. Brown, M. Virreira, E. Hupkens, J. Perret, O. Devuyst, S. Uchida, C. Delporte, W.J. Malaisse, et al., A new role for aquaporin 7 in insulin secretion, Cell. Physiol. Biochem. 29 (2012) 65-74, https://doi.org/ $10.1159 / 000337588$.

[28] C. Delporte, M. Virreira, R. Crutzen, K. Louchami, A. Sener, W.J. Malaisse, R. Beauwens, Functional role of aquaglyceroporin 7 expression in the pancreatic beta-cell line BRIN-BD11, J. Cell. Physiol. 221 (2009) 424-429, https://doi.org/10.1002/jcp.21872.

[29] J.S. Jung, G.M. Preston, B.L. Smith, W.B. Guggino, P. Agre, Molecular structure of the water channel through aquaporin CHIP. The hourglass model, J. Biol. Chem. 269 (1994) 14648-14654.

[30] D. Krenc, J. Song, A. Almasalmeh, B. Wu, E. Beitz, The arginine-facing amino acid residue of the rat aquaporin 1 constriction determines solute selectivity according to its size and lipophilicity, Mol. Membr. Biol. 31 (2014) 228-238, https://doi.org/10.3109/09687688.2014.960493.

[31] E. Beitz, B. Wu, L.M. Holm, J.E. Schultz, T. Zeuthen, Point mutations in the aromatic/arginine region in aquaporin 1 allow passage of urea, glycerol, ammonia, and protons, Proc. Natl. Acad. Sci. U. S. A. 103 (2006) 269-274, https://doi.org/10.1073/pnas.0507225103.

[32] U.K. Eriksson, G. Fischer, R. Friemann, G. Enkavi, E. Tajkhorshid, R. Neutze, Subangstrom resolution X-ray structure details aquaporin-water interactions, Science 340 (2013) 1346-1349, https://doi.org/10.1126/ science.1234306.

[33] N. Chakrabarti, B. Roux, R. Pomès, Structural determinants of proton blockage in aquaporins, J. Mol. Biol. 343 (2004) 493-510, https://doi.org/ 10.1016/j.jmb.2004.08.036.

[34] R. Oliva, G. Calamita, J.M. Thornton, M. Pellegrini-Calace, Electrostatics of aquaporin and aquaglyceroporin channels correlates with their transport selectivity, Proc. Natl. Acad. Sci. U.S.A. 107 (2010) 4135-4140, https:// doi.org/10.1073/pnas.0910632107.

[35] D. Wragg, A. de Almeida, A. Casini, S. Leoni, Unveiling the mechanisms of aquaglyceroporin-3 water and glycerol permeation by metadynamics, Chemistry 25 (2019) 8713-8718, https://doi.org/10.1002/chem.201902121.

[36] Y. Kato, T. Miyauchi, Y. Abe, D. Kojić, M. Tanaka, N. Chikazawa, Y. Nakatake, S.B.H. Ko, D. Kobayashi, A. Hazama, et al., Unprecedented cell-selection using ultra-quick freezing combined with aquaporin expression, PloS One 9 (2014), e87644, https://doi.org/10.1371/journal.pone.0087644.

[37] G. Portella, P. Pohl, B.L. de Groot, Invariance of single-file water mobility in gramicidin-like peptidic pores as function of pore length, Biophys. J. 92 (2007) 3930-3937, https://doi.org/10.1529/biophysj.106.102921.

[38] D. Fu, A. Libson, L.J. Miercke, C. Weitzman, P. Nollert, J. Krucinski, R.M. Stroud, Structure of a glycerol-conducting channel and the basis for its selectivity, Science 290 (2000) 481-486, https://doi.org/10.1126/science.290.5491.481.

[39] H. Viadiu, T. Gonen, T. Walz, Projection map of aquaporin-9 at 7 A resolution, J. Mol. Biol. 367 (2007) 80-88, https://doi.org/10.1016/j.jmb.2006.12.042.

[40] H. Sui, B.G. Han, J.K. Lee, P. Walian, B.K. Jap, Structural basis of water-specific transport through the AQP1 water channel, Nature 414 (2001) 872-878, https://doi.org/10.1038/414872a.

[41] P. Kitchen, M.M. Salman, S.U. Pickel, J. Jennings, S. Törnroth-Horsefield, M.T. Conner, R.M. Bill, A.C. Conner, Water channel pore size determines exclusion properties but not solute selectivity, Sci. Rep. 9 (2019), 20369, https://doi.org/10.1038/s41598-019-56814-z.

[42] A. Spinello, A. de Almeida, A. Casini, G. Barone, The inhibition of glycerol permeation through aquaglyceroporin-3 induced by mercury(II): a molecular dynamics study, J. Inorg. Biochem. 160 (2016) 78-84, https://doi.org/ 10.1016/j.jinorgbio.2015.11.027.

[43] A. de Almeida, A.F. Mósca, D. Wragg, M. Wenzel, P. Kavanagh, G. Barone, S. Leoni, G. Soveral, A. Casini, The mechanism of aquaporin inhibition by gold compounds elucidated by biophysical and computational methods, Chem. Commun. (Camb.) 53 (2017) 3830-3833, https://doi.org/10.1039/ c7cc00318h.

[44] J.S. Hub, B.L. de Groot, Mechanism of selectivity in aquaporins and aquaglyceroporins, Proc. Natl. Acad. Sci. U.S.A. 105 (2008) 1198-1203, https:// doi.org/10.1073/pnas.0707662104.

[45] B. Yang, A.S. Verkman, Water and glycerol permeabilities of aquaporins 1-5 and MIP determined quantitatively by expression of epitope-tagged constructs in Xenopus oocytes, J. Biol. Chem. 272 (1997) 16140-16146, https:// doi.org/10.1074/jbc.272.26.16140.

[46] R.A. Rodriguez, H. Liang, L.Y. Chen, G. Plascencia-Villa, G. Perry, Singlechannel permeability and glycerol affinity of human aquaglyceroporin AQP3, Biochim. Biophys. Acta Biomembr. 1861 (2019) 768-775, https://doi.org/ 10.1016/j.bbamem.2019.01.008.

[47] T. Zeuthen, D.A. Klaerke, Transport of water and glycerol in aquaporin 3 is gated by $\mathrm{H}(+)$, J. Biol. Chem. 274 (1999) 21631-21636, https://doi.org/ 10.1074/jbc.274.31.21631.

[48] E.W. Miller, B.C. Dickinson, C.J. Chang, Aquaporin-3 mediates hydrogen peroxide uptake to regulate downstream intracellular signaling, Proc. Natl. Acad. Sci. U.S.A. 107 (2010) 15681-15686, https://doi.org/10.1073/ pnas. 1005776107.

[49] A. Müller-Lucks, P. Gena, D. Frascaria, N. Altamura, M. Svelto, E. Beitz, G. Calamita, Preparative scale production and functional reconstitution of a human aquaglyceroporin (AQP3) using a cell free expression system, Nat. Biotechnol. 30 (2013) 545-551, https://doi.org/10.1016/j.nbt.2013.03.007.

[50] Y. Sonntag, P. Gena, A. Maggio, T. Singh, I. Artner, M.K. Oklinski, U. Johanson, P. Kjellbom, J.D. Nieland, S. Nielsen, et al., Identification and characterization of potent and selective aquaporin-3 and aquaporin-7 inhibitors, J. Biol. Chem. 294 (2019) 7377-7387, https://doi.org/10.1074/jbc.RA118.006083.

[51] M. Echevarria, E.E. Windhager, S.S. Tate, G. Frindt, Cloning and expression of AQP3, a water channel from the medullary collecting duct of rat kidney, Proc. Natl. Acad. Sci. U. S. A. 91 (1994) 10997-11001, https://doi.org/10.1073/ pnas.91.23.10997.

[52] K. Ishibashi, S. Sasaki, K. Fushimi, S. Uchida, M. Kuwahara, H. Saito, T. Furukawa, K. Nakajima, Y. Yamaguchi, T. Gojobori, Molecular cloning and expression of a member of the aquaporin family with permeability to glycerol and urea in addition to water expressed at the basolateral membrane of kidney collecting duct cells, Proc. Natl. Acad. Sci. U. S. A. 91 (1994) 6269-6273, https://doi.org/10.1073/pnas.91.14.6269.

[53] P. Kitchen, F. Öberg, J. Sjöhamn, K. Hedfalk, R.M. Bill, A.C. Conner, M.T. Conner, S. Törnroth-Horsefield, Plasma membrane abundance of human aquaporin 5 is dynamically regulated by multiple pathways, PloS One 10 (2015), e0143027, https://doi.org/10.1371/journal.pone.0143027.

[54] K. Ishibashi, M. Kuwahara, Y. Gu, Y. Kageyama, A. Tohsaka, F. Suzuki, F. Marumo, S. Sasaki, Cloning and functional expression of a new water channel abundantly expressed in the testis permeable to water, glycerol, and urea, J. Biol. Chem. 272 (1997) 20782-20786.

[55] K. Ishibashi, K. Yamauchi, Y. Kageyama, F. Saito-Ohara, T. Ikeuchi, F. Marumo, S. Sasaki, Molecular characterization of human aquaporin-7 gene and its chromosomal mapping, Biochim. Biophys. Acta 1399 (1998) 62-66.

[56] A. Rojek, J. Praetorius, J. Frøkiaer, S. Nielsen, R.A. Fenton, A current view of the mammalian aquaglyceroporins, Annu. Rev. Physiol. 70 (2008) 301-327, https://doi.org/10.1146/annurev.physiol.70.113006.100452.

[57] F.J. Moss, P. Mahinthichaichan, D.T. Lodowski, T. Kowatz, E. Tajkhorshid, A. Engel, W.F. Boron, A. Vahedi-Faridi, Aquaporin-7: a dynamic aquaglyceroporin with greater water and glycerol permeability than its bacterial homolog GlpF, Front. Physiol. 11 (2020) 728, https://doi.org/10.3389/ fphys.2020.00728.

[58] T. Katano, Y. Ito, K. Ohta, T. Yasujima, K. Inoue, H. Yuasa, Functional characteristics of aquaporin 7 as a facilitative glycerol carrier, Drug Metabol. Pharmacokinet. 29 (2014) 244-248, https://doi.org/10.2133/dmpk.dmpk13-rg-121.

[59] M. Palmgren, M. Hernebring, S. Eriksson, K. Elbing, C. Geijer, S. Lasič, P. Dahl, J.S. Hansen, D. Topgaard, K. Lindkvist-Petersson, Quantification of the intracellular life time of water molecules to measure transport rates of 
human aquaglyceroporins, J. Membr. Biol. 250 (2017) 629-639, https:// doi.org/10.1007/s00232-017-9988-4.

[60] K. Gotfryd, A.F. Mósca, J.W. Missel, S.F. Truelsen, K. Wang, M. Spulber, S. Krabbe, C. Hélix-Nielsen, U. Laforenza, G. Soveral, et al., Human adipose glycerol flux is regulated by a PH gate in AQP10, Nat. Commun. 9 (2018) 4749, https://doi.org/10.1038/s41467-018-07176-z.

[61] S.W. de Maré, R. Venskutonytè, S. Eltschkner, B.L. de Groot, K. LindkvistPetersson, Structural basis for glycerol efflux and selectivity of human aquaporin 7, Structure 28 (2020) 215-222, https://doi.org/10.1016/ j.str.2019.11.011, e3.

[62] M.O. Jensen, E. Tajkhorshid, K. Schulten, The mechanism of glycerol conduction in aquaglyceroporins, Structure 9 (2001) 1083-1093, https:// doi.org/10.1016/s0969-2126(01)00668-2.

[63] A.F. Mósca, A. de Almeida, D. Wragg, A.P. Martins, F. Sabir, S. Leoni, T.F. Moura, C. Prista, A. Casini, G. Soveral, Molecular basis of aquaporin-7 permeability regulation by $\mathrm{PH}$, Cells 7 (2018), https://doi.org/10.3390/ cells7110207.

[64] S. Watanabe, C.S. Moniaga, S. Nielsen, M. Hara-Chikuma, Aquaporin-9 facilitates membrane transport of hydrogen peroxide in mammalian cells, Biochem. Biophys. Res. Commun. 471 (2016) 191-197, https://doi.org/10.1016/ j.bbrc.2016.01.153.

[65] A.S. Verkman, A.K. Mitra, Structure and function of aquaporin water channels, Am. J. Physiol. Ren. Physiol. 278 (2000) F13-F28, https://doi.org/ 10.1152/ajprenal.2000.278.1.F13.

[66] L. Reshef, Y. Olswang, H. Cassuto, B. Blum, C.M. Croniger, S.C. Kalhan, S.M. Tilghman, R.W. Hanson, Glyceroneogenesis and the triglyceride/fatty acid cycle, J. Biol. Chem. 278 (2003) 30413-30416, https://doi.org/10.1074/ jbc.R300017200.

[67] M.S. Hedrington, S.N. Davis, Sexual dimorphism in glucose and lipid metabolism during fasting, hypoglycemia, and exercise, Front. Endocrinol. 6 (2015) 61, https://doi.org/10.3389/fendo.2015.00061

[68] F. Gregoire, V. Lucidi, A. Zerrad-Saadi, M. Virreira, N. Bolaky, V. Delforge, A. Lemmers, V. Donckier, J. Devière, P. Demetter, et al., Analysis of aquaporin expression in liver with a focus on hepatocytes, Histochem. Cell Biol. 144 (2015) 347-363, https://doi.org/10.1007/s00418-015-1341-3.

[69] A. Rodríguez, P. Gena, L. Méndez-Giménez, A. Rosito, V. Valentí, F. Rotellar, I. Sola, R. Moncada, C. Silva, M. Svelto, et al., Reduced hepatic aquaporin-9 and glycerol permeability are related to insulin resistance in non-alcoholic fatty liver disease, Int. J. Obes. 38 (2014) 1213-1220, https://doi.org/ 10.1038/ijo.2013.234.

[70] M. Tardelli, F.V. Bruschi, T. Claudel, V. Moreno-Viedma, E. Halilbasic, F. Marra, M. Herac, T.M. Stulnig, M. Trauner, AQP3 is regulated by PPAR $\gamma$ and JNK in hepatic stellate cells carrying PNPLA3 I148M, Sci. Rep. 7 (2017), 14661, https://doi.org/10.1038/s41598-017-14557-9.

[71] M. Elkjaer, Z. Vajda, L.N. Nejsum, T. Kwon, U.B. Jensen, M. Amiry-Moghaddam, J. Frøkiaer, S. Nielsen, Immunolocalization of AQP9 in liver, epididymis, testis, spleen, and brain, Biochem. Biophys. Res. Commun. 276 (2000) 1118-1128, https://doi.org/10.1006/bbrc.2000.3505.

[72] S. Jelen, S. Wacker, C. Aponte-Santamaría, M. Skott, A. Rojek, U. Johanson, P. Kjellbom, S. Nielsen, B.L. de Groot, M. Rützler, Aquaporin-9 protein is the primary route of hepatocyte glycerol uptake for glycerol gluconeogenesis in mice, J. Biol. Chem. 286 (2011) 44319-44325, https://doi.org/10.1074/ jbc.M111.297002.

[73] A.M. Rojek, M.T. Skowronski, E.-M. Füchtbauer, A.C. Füchtbauer, R.A. Fenton, P. Agre, J. Frøkiaer, S. Nielsen, Defective glycerol metabolism in aquaporin 9 (AQP9) knockout mice, Proc. Natl. Acad. Sci. U. S. A. 104 (2007) 3609-3614, https://doi.org/10.1073/pnas.0610894104.

[74] G. Calamita, D. Ferri, P. Gena, F.I. Carreras, G.E. Liquori, P. Portincasa, R.A. Marinelli, M. Svelto, Altered expression and distribution of aquaporin-9 in the liver of rat with obstructive extrahepatic cholestasis, Am. J. Physiol. Gastrointest. Liver Physiol. 295 (2008) G682-G690, https://doi.org/10.1152/ ajpgi.90226.2008.

[75] A. Rodríguez, V. Catalán, J. Gómez-Ambrosi, S. García-Navarro, F. Rotellar, V. Valentí, C. Silva, M.J. Gil, J. Salvador, M.A. Burrell, et al., Insulin- and leptinmediated control of aquaglyceroporins in human adipocytes and hepatocytes is mediated via the PI3K/akt/MTOR signaling cascade, J. Clin. Endocrinol. Metab. 96 (2011) E586-E597, https://doi.org/10.1210/jc.2010-1408.

[76] S. Jelen, P. Gena, J. Lebeck, A. Rojek, J. Praetorius, J. Frøkiaer, R.A. Fenton, S. Nielsen, G. Calamita, M. Rützler, Aquaporin-9 and urea transporter-A gene deletions affect urea transmembrane passage in murine hepatocytes, Am. J. Physiol. Gastrointest. Liver Physiol. 303 (2012) G1279-G1287, https:// doi.org/10.1152/ajpgi.00153.2012.

[77] J.M. Carbrey, L. Song, Y. Zhou, M. Yoshinaga, A. Rojek, Y. Wang, Y. Liu, H.L. Lujan, S.E. DiCarlo, S. Nielsen, et al., Reduced arsenic clearance and increased toxicity in aquaglyceroporin-9-null mice, Proc. Natl. Acad. Sci. U.S.A. 106 (2009) 15956-15960, https://doi.org/10.1073/pnas.0908108106.

[78] C. Lindskog, A. Asplund, A. Catrina, S. Nielsen, M. Rützler, A systematic characterization of aquaporin-9 expression in human normal and pathological tissues, J. Histochem. Cytochem. 64 (2016) 287-300, https://doi.org/ 10.1369/0022155416641028.

[79] P. Portincasa, A. Moschetta, A. Mazzone, G. Palasciano, M. Svelto, G. Calamita, Water handling and aquaporins in bile formation: recent advances and research trends, J. Hepatol. 39 (2003) 864-874, https://doi.org/10.1016/ s0168-8278(03)00294-0.

[80] G.P. Nicchia, A. Frigeri, B. Nico, D. Ribatti, M. Svelto, Tissue distribution and membrane localization of aquaporin-9 water channel: evidence for sexlinked differences in liver, J. Histochem. Cytochem. 49 (2001) 1547-1556, https://doi.org/10.1177/002215540104901208.

[81] F.M. Iena, J.B. Jul, J.B. Vegger, A. Lodberg, J.S. Thomsen, A. Brüel, J. Lebeck, Sexspecific effect of high-fat diet on glycerol metabolism in murine adipose tissue and liver, Front. Endocrinol. 11 (2020), 577650, https://doi.org/ 10.3389/fendo.2020.577650.

[82] M. Tardelli, V. Moreno-Viedma, M. Zeyda, B.K. Itariu, F.B. Langer, G. Prager T.M. Stulnig, Adiponectin regulates aquaglyceroporin expression in hepatic stellate cells altering their functional state, J. Gastroenterol. Hepatol. 32 (2017) 253-260, https://doi.org/10.1111/jgh.13415.

[83] G. Calamita, P. Gena, D. Ferri, A. Rosito, A. Rojek, S. Nielsen, R.A. Marinelli, G. Frühbeck, M. Svelto, Biophysical assessment of aquaporin-9 as principal facilitative pathway in mouse liver import of glucogenetic glycerol, Biol. Cell. 104 (2012) 342-351, https://doi.org/10.1111/boc.201100061.

[84] C.C. Li, E.C. Lin, Glycerol transport and phosphorylation by rat hepatocytes, J. Cell. Physiol. 117 (1983) 230-234, https://doi.org/10.1002/ jcp. 1041170214.

[85] D. Brisson, M.C. Vohl, J. St-Pierre, T.J. Hudson, D. Gaudet, Glycerol: a neglected variable in metabolic processes? Bioessays 23 (2001) 534-542. https://doi.org/10.1002/bies.1073.

[86] P. Portincasa, G. Calamita, Water channel proteins in bile formation and flow in health and disease: when immiscible becomes miscible, Mol. Aspect. Med. 33 (2012) 651-664, https://doi.org/10.1016/j.mam.2012.03.010.

[87] H. Kuriyama, I. Shimomura, K. Kishida, H. Kondo, N. Furuyama, H. Nishizawa, N. Maeda, M. Matsuda, H. Nagaretani, S. Kihara, et al., Coordinated regulation of fat-specific and liver-specific glycerol channels, aquaporin adipose and aquaporin 9, Diabetes 51 (2002) 2915-2921.

[88] J.M. Carbrey, D.A. Gorelick-Feldman, D. Kozono, J. Praetorius, S. Nielsen, P. Agre, Aquaglyceroporin AOP9: solute permeation and metabolic control of expression in liver, Proc. Natl. Acad. Sci. U.S.A. 100 (2003) 2945-2950, https://doi.org/10.1073/pnas.0437994100.

[89] P. Gena, N.D. Buono, M. D’Abbicco, M. Mastrodonato, M. Berardi, M. Svelto, L. Lopez, G. Calamita, Dynamical modeling of liver aquaporin-9 expression and glycerol permeability in hepatic glucose metabolism, Eur. J. Cell Biol. 96 (2017) 61-69, https://doi.org/10.1016/j.ejcb.2016.12.003.

[90] J. Lebeck, Metabolic impact of the glycerol channels AQP7 and AQP9 in adipose tissue and liver, J. Mol. Endocrinol. 52 (2014) R165-R178, https:// doi.org/10.1530/JME-13-0268.

[91] Y. Yokoyama, K. Iguchi, S. Usui, K. Hirano, AMP-activated protein kinase modulates the gene expression of aquaporin 9 via forkhead box A2, Arch. Biochem. Biophys. 515 (2011) 80-88, https://doi.org/10.1016/ j.abb.2011.08.002.

[92] S. Usui, M. Soda, K. Iguchi, N. Abe, M. Oyama, T. Nakayama, K. Kitaichi, Downregulation of aquaporin 9 gene transcription by 10-hydroxy-2-decenoic acid: a major fatty acid in royal jelly, Food Sci. Nutr. 7 (2019) 3819-3826, https:// doi.org/10.1002/fsn3.1246.

[93] J. Lebeck, T. Østergård, A. Rojek, E.-M. Füchtbauer, S. Lund, S. Nielsen, J. Praetorius, Gender-specific effect of physical training on AQP7 protein expression in human adipose tissue, Acta Diabetol. 49 (Suppl 1) (2012) S215-S226, https://doi.org/10.1007/s00592-012-0430-1.

[94] J. Lebeck, M.U. Cheema, M.T. Skowronski, S. Nielsen, J. Praetorius, Hepatic AQP9 expression in male rats is reduced in response to PPAR $\alpha$ agonist treatment, Am. J. Physiol. Gastrointest. Liver Physiol. 308 (2015) G198-G205, https://doi.org/10.1152/ajpgi.00407.2013.

[95] C. Cai, C. Wang, W. Ji, B. Liu, Y. Kang, Z. Hu, Z. Jiang, Knockdown of hepatic aquaglyceroporin-9 alleviates high fat diet-induced non-alcoholic fatty liver disease in rats, Int. Immunopharm. 15 (2013) 550-556, https://doi.org/ 10.1016/j.intimp.2013.01.020.

[96] S. Hirako, Y. Wakayama, H. Kim, Y. Iizuka, A. Matsumoto, N. Wada, A. Kimura, M. Okabe, J. Sakagami, M. Suzuki, et al., The relationship between aquaglyceroporin expression and development of fatty liver in diet-induced obesity and ob/ob mice, Obes. Res. Clin. Pract. 10 (2016) 710-718, https:// doi.org/10.1016/j.orcp.2015.12.001.

[97] P. Gena, M. Mastrodonato, P. Portincasa, E. Fanelli, D. Mentino, A. Rodríguez, R.A. Marinelli, C. Brenner, G. Frühbeck, M. Svelto, et al., Liver glycerol permeability and aquaporin-9 are dysregulated in a murine model of nonalcoholic fatty liver disease, PloS One 8 (2013), e78139, https://doi.org/ 10.1371/journal.pone.0078139.

[98] J.M. Peace, M.G. Hire, F.M. Peralta, Postpartum thyroid storm in poorly controlled graves' disease: a case report, In Pract. 13 (2019) 299-302, https://doi.org/10.1213/XAA.0000000000001059.

[99] F. Baldini, P. Portincasa, E. Grasselli, G. Damonte, A. Salis, M. Bonomo, M. Florio, N. Serale, A. Voci, P. Gena, et al., Aquaporin-9 is involved in the lipid-lowering activity of the nutraceutical silybin on hepatocytes through modulation of autophagy and lipid droplets composition, Biochim. Biophys. Acta Mol. Cell Biol. Lipids 1865 (2020) 158586, https://doi.org/10.1016/ j.bbalip.2019.158586.

[100] N. Chalasani, Z. Younossi, J.E. Lavine, A.M. Diehl, E.M. Brunt, K. Cusi, M. Charlton, A.J. Sanyal, American Gastroenterological Association; American Association for the Study of Liver Diseases; et al. The Diagnosis and Management of Non-Alcoholic Fatty Liver Disease: practice Guideline by the American Gastroenterological Association, American Association for the Study of Liver Diseases, and American College of Gastroenterology, Gastro-

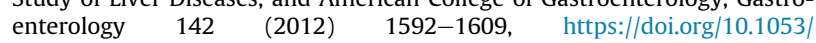


j.gastro.2012.04.001

[101] M. Miranda, V. Ceperuelo-Mallafré, A. Lecube, C. Hernandez, M.R. Chacon, J.M. Fort, L. Gallart, J.A. Baena-Fustegueras, R. Simó, J. Vendrell, Gene expression of paired abdominal adipose AQP7 and liver AQP9 in patients with morbid obesity: relationship with glucose abnormalities, Metab. Clin. Exp. 58 (2009) 1762-1768, https://doi.org/10.1016/j.metabol.2009.06.004.

[102] P. Spegel, A. Chawade, S. Nielsen, P. Kjellbom, M. Rützler, Deletion of glycerol channel aquaporin-9 (Aqp9) impairs long-term blood glucose control in C57BL/6 leptin receptor-deficient (Db/Db) obese mice, Phys. Rep. 3 (2015), https://doi.org/10.14814/phy2.12538.

[103] C. Wang, Z.-L. Lv, Y.-J. Kang, T.-X. Xiang, P.-L. Wang, Z. Jiang, Aquaporin-9 downregulation prevents steatosis in oleic acid-induced non-alcoholic fatty liver disease cell models, Int. J. Mol. Med. 32 (2013) 1159-1165, https:// doi.org/10.3892/ijmm.2013.1502.

[104] G. Calamita, P. Portincasa, Present and future therapeutic strategies in nonalcoholic fatty liver disease, Expert Opin. Ther. Targets 11 (2007) 1231-1249, https://doi.org/10.1517/14728222.11.9.1231.

[105] J.J. Potter, A. Koteish, J. Hamilton, X. Liu, K. Liu, P. Agre, E. Mezey, Effects of acetaldehyde on hepatocyte glycerol uptake and cell size: implication of aquaporin 9, Alcohol Clin. Exp. Res. 35 (2011) 939-945, https://doi.org/ 10.1111/j.1530-0277.2010.01424.x.

[106] X. Fu, L. Xing, W. Xu, J. Shu, Treatment with estrogen protects against ovariectomy-induced hepatic steatosis by increasing AQP7 expression, Mol. Med. Rep. 14 (2016) 425-431, https://doi.org/10.3892/mmr.2016.5236.

[107] G. Frühbeck, V. Catalán, J. Gómez-Ambrosi, A. Rodríguez, Aquaporin-7 and glycerol permeability as novel obesity drug-target pathways, Trends Pharmacol. Sci. 27 (2006) 345-347, https://doi.org/10.1016/j.tips.2006.05.002.

[108] N. Maeda, T. Hibuse, T. Funahashi, Role of aquaporin-7 and aquaporin-9 in glycerol metabolism; involvement in obesity, Handb. Exp. Pharmacol. (2009) 233-249, https://doi.org/10.1007/978-3-540-79885-9 12.

[109] A. Madeira, T.F. Moura, G. Soveral, Aquaglyceroporins: implications in adipose biology and obesity, Cell. Mol. Life Sci. 72 (2015) 759-771, https:// doi.org/10.1007/s00018-014-1773-2.

[110] U. Laforenza, C. Bottino, G. Gastaldi, Mammalian aquaglyceroporin function in metabolism, Biochim. Biophys. Acta 1858 (2016) 1-11, https://doi.org/ 10.1016/j.bbamem.2015.10.004.

[111] I.V. da Silva, G. Soveral, Aquaporins in obesity, Adv. Exp. Med. Biol. 969 (2017) 227-238, https://doi.org/10.1007/978-94-024-1057-0_15.

[112] L. Méndez-Giménez, S. Ezquerro, I.V. da Silva, G. Soveral, G. Frühbeck, A. Rodríguez, Pancreatic aquaporin-7: a novel target for anti-diabetic drugs? Front Chem 6 (2018) 99, https://doi.org/10.3389/fchem.2018.00099.

[113] H. Kondo, I. Shimomura, K. Kishida, H. Kuriyama, Y. Makino, H. Nishizawa, M. Matsuda, N. Maeda, H. Nagaretani, S. Kihara, et al., Human aquaporin adipose (AQPap) gene. Genomic structure, promoter analysis and functional mutation, Eur. J. Biochem. 269 (2002) 1814-1826.

[114] M. Miranda, X. Escoté, V. Ceperuelo-Mallafré, M.J. Alcaide, I. Simón, N. Vilarrasa, M. Wabitsch, J. Vendrell, Paired subcutaneous and visceral adipose tissue aquaporin-7 expression in human obesity and type 2 diabetes: differences and similarities between depots, J. Clin. Endocrinol. Metab. 95 (2010) 3470-3479, https://doi.org/10.1210/jc.2009-2655.

[115] U. Laforenza, M.F. Scaffino, G. Gastaldi, Aquaporin-10 represents an alternative pathway for glycerol efflux from human adipocytes, PloS One 8 (2013), e54474, https://doi.org/10.1371/journal.pone.0054474.

[116] A. Madeira, S. Fernández-Veledo, M. Camps, A. Zorzano, T.F. Moura, V. Ceperuelo-Mallafré, J. Vendrell, G. Soveral, Human aquaporin-11 is a water and glycerol channel and localizes in the vicinity of lipid droplets in human adipocytes, Obesity 22 (2014) 2010-2017, https://doi.org/10.1002/ oby. 20792.

[117] G. Frühbeck, I. Balaguer, L. Méndez-Giménez, V. Valentí, S. Becerril, V. Catalán, J. Gómez-Ambrosi, C. Silva, J. Salvador, G. Calamita, et al., Aquaporin-11 contributes to TGF-ß1-induced endoplasmic reticulum stress in human visceral adipocytes: role in obesity-associated inflammation, Cells 9 (2020), https://doi.org/10.3390/cells9061403.

[118] K. Kishida, I. Shimomura, H. Nishizawa, N. Maeda, H. Kuriyama, H. Kondo, M. Matsuda, H. Nagaretani, N. Ouchi, K. Hotta, et al., Enhancement of the aquaporin adipose gene expression by a peroxisome proliferator-activated receptor gamma, J. Biol. Chem. 276 (2001) 48572-48579, https://doi.org/ 10.1074/jbc.M108213200.

[119] K. Kishida, H. Kuriyama, T. Funahashi, I. Shimomura, S. Kihara, N. Ouchi, M. Nishida, H. Nishizawa, M. Matsuda, M. Takahashi, et al., Aquaporin adipose, a putative glycerol channel in adipocytes, J. Biol. Chem. 275 (2000) 20896-20902, https://doi.org/10.1074/jbc.M001119200.

[120] N. Maeda, T. Funahashi, T. Hibuse, A. Nagasawa, K. Kishida, H. Kuriyama, T. Nakamura, S. Kihara, I. Shimomura, Y. Matsuzawa, Adaptation to fasting by glycerol transport through aquaporin 7 in adipose tissue, Proc. Natl. Acad. Sci. U.S.A. 101 (2004) 17801-17806, https://doi.org/10.1073/ pnas.0406230101.

[121] M.T. Skowronski, J. Lebeck, A. Rojek, J. Praetorius, E.-M. Füchtbauer, J. Frøkiaer, S. Nielsen, AQP7 is localized in capillaries of adipose tissue, cardiac and striated muscle: implications in glycerol metabolism, Am. J. Physiol. Ren. Physiol. 292 (2007) F956-F965, https://doi.org/10.1152/ ajprenal.00314.2006.

[122] T. Miyauchi, H. Yamamoto, Y. Abe, G.J. Yoshida, A. Rojek, E. Sohara, S. Uchida, S. Nielsen, M. Yasui, Dynamic subcellular localization of aquaporin-7 in white adipocytes, FEBS Lett. 589 (2015) 608-614, https://doi.org/10.1016/ j.febslet.2015.01.025

[123] T. Arsenijevic, F. Gregoire, J. Chiadak, E. Courtequisse, N. Bolaky, J. Perret, C. Delporte, Pituitary adenylate cyclase activating peptide (PACAP) participates in adipogenesis by activating ERK signaling pathway, PloS One 8 (2013), e72607, https://doi.org/10.1371/journal.pone.0072607.

[124] J.D. Chiadak, T. Arsenijevic, K. Verstrepen, F. Gregoire, N. Bolaky, V. Delforge, V. Flamand, J. Perret, C. Delporte, Forskolin inhibits lipopolysaccharideinduced modulation of MCP-1 and GPR120 in 3T3-L1 adipocytes through an inhibition of NFKB, Mediat. Inflamm. 2016 (2016), 1431789, https:// doi.org/10.1155/2016/1431789.

[125] J.D. Chiadak, T. Arsenijevic, F. Gregoire, N. Bolaky, V. Delforge, J. Perret, C. Delporte, Involvement of JNK/NFkappaB signaling pathways in the Copolysaccharide-induced modulation of aquaglyceroporin expression in 3T3-L1 cells differentiated into adipocytes, Int. J. Mol. Sci. 17 (2016), https:// doi.org/10.3390/ijms17101742.

[126] J.D. Chiadak, P. Gena, F. Gregoire, N. Bolaky, V. Delforge, J. Perret, G. Calamita C. Delporte, Lipopolysaccharide modifies glycerol permeability and metabolism in 3T3-L1 adipocytes, Int. J. Mol. Sci. 18 (2017), https://doi.org/ 10.3390/ijms18122566.

[127] T. Morinaga, M. Nakakoshi, A. Hirao, M. Imai, K. Ishibashi, Mouse aquaporin 10 gene (AQP10) is a pseudogene, Biochem. Biophys. Res. Commun. 294 (2002) 630-634, https://doi.org/10.1016/S0006-291X(02)00536-3.

[128] I.V. da Silva, F. Díaz-Sáez, A. Zorzano, A. Gumà, M. Camps, G. Soveral Aquaglyceroporins are differentially expressed in beige and white adipocytes, Int. J. Mol. Sci. (2020) 21, https://doi.org/10.3390/ijms21020610.

[129] S. Gómez-Zorita, J. Trepiana, A. Fernández-Quintela, M. González, M.P. Portillo, Resveratrol and pterostilbene, two analogue phenolic compounds, affect aquaglyceroporin expression in a different manner in adipose tissue, Int. J. Mol. Sci. 19 (2018), https://doi.org/10.3390/ijms19092654.

[130] A. Rodríguez, S. Ezquerro, L. Méndez-Giménez, S. Becerril, G. Frühbeck, Revisiting the adipocyte: a model for integration of cytokine signaling in the regulation of energy metabolism, Am. J. Physiol. Endocrinol. Metab. 309 (2015) E691-E714, https://doi.org/10.1152/ajpendo.00297.2015.

[131] J.S. Hansen, S. de Maré, H.A. Jones, O. Göransson, K. Lindkvist-Petersson, Visualization of lipid directed dynamics of perilipin 1 in human primary adipocytes, Sci. Rep. 7 (2017), 15011, https://doi.org/10.1038/s41598-01715059-4.

[132] M. Fasshauer, J. Klein, U. Lossner, M. Klier, S. Kralisch, R. Paschke, Suppression of aquaporin adipose gene expression by isoproterenol, TNFalpha, and dexamethasone, Horm. Metab. Res. 35 (2003) 222-227, https://doi.org/ $10.1055 / \mathrm{s}-2003-39478$.

[133] C.M. Lindgren, M.M. Mahtani, E. Widén, M.I. McCarthy, M.J. Daly, A. Kirby, M.P. Reeve, L. Kruglyak, A. Parker, J. Meyer, et al., Genomewide search for type 2 diabetes mellitus susceptibility loci in Finnish families: the botnia study, Am. J. Hum. Genet. 70 (2002) 509-516, https://doi.org/10.1086/ 338629.

[134] A. Kulyté, A. Ehrlund, P. Arner, I. Dahlman, Global transcriptome profiling identifies KLF15 and SLC25A10 as modifiers of adipocytes insulin sensitivity in obese women, PloS One 12 (2017), e0178485, https://doi.org/10.1371/ journal.pone.0178485.

[135] G. Agha, E.A. Houseman, K.T. Kelsey, C.B. Eaton, S.L. Buka, E.B. Loucks, Adiposity is associated with DNA methylation profile in adipose tissue, Int. J. Epidemiol. 44 (2015) 1277-1287, https://doi.org/10.1093/ije/dyu236.

[136] A.G. Kerr, I. Sinha, S. Dadvar, P. Arner, I. Dahlman, Epigenetic regulation of diabetogenic adipose morphology, Mol Metab 25 (2019) 159-167, https:/ doi.org/10.1016/j.molmet.2019.04.009.

[137] A. Gomes, I.V. da Silva, C.M.P. Rodrigues, R.E. Castro, G. Soveral, The emerging role of MicroRNAs in aquaporin regulation, Front Chem 6 (2018) 238, https:// doi.org/10.3389/fchem.2018.00238.

[138] D.S. Karolina, A. Armugam, S. Sepramaniam, S.L.T. Pek, M.T. Wong, S.C. Lim, C.F. Sum, S. Tavintharan, Jeyaseelan, Iah MiR-22 and MiR-23a Control Glycerol-dependent Gluconeogenesis by Regulating Aquaporin 9 Expression, 2014, https://doi.org/10.4172/2153-0769.S2-002.

[139] A. de Almeida, A.P. Martins, A.F. Mósca, H.J. Wijma, C. Prista, G. Soveral, A. Casini, Exploring the gating mechanisms of aquaporin-3: new clues for the design of inhibitors? Mol. Biosyst. 12 (2016) 1564-1573, https://doi.org/ 10.1039/C6MB00013D.

[140] T. Ma, H. Hasegawa, W.R. Skach, A. Frigeri, A.S. Verkman, Expression, functional analysis, and in situ hybridization of a cloned rat kidney collecting duct water channel, Am. J. Physiol. 266 (1994) C189-C197, https://doi.org/ 10.1152/ajpcell.1994.266.1.C189.

[141] M. Zelenina, A.A. Bondar, S. Zelenin, A. Aperia, Nickel and extracellular acidification inhibit the water permeability of human aquaporin-3 in lung epithelial cells, J. Biol. Chem. 278 (2003) 30037-30043, https://doi.org/ 10.1074/jbc.M302206200.

[142] H. Yasui, M. Kubota, K. Iguchi, S. Usui, T. Kiho, K. Hirano, Membrane trafficking of aquaporin 3 induced by epinephrine, Biochem. Biophys. Res. Commun. 373 (2008) 613-617, https://doi.org/10.1016/j.bbrc.2008.06.086.

[143] P. Arner, Human fat cell lipolysis: biochemistry, regulation and clinical role Best Pract. Res. Clin. Endocrinol. Metabol. 19 (2005) 471-482, https:// doi.org/10.1016/j.beem.2005.07.004.

[144] T. Hibuse, N. Maeda, T. Funahashi, K. Yamamoto, A. Nagasawa, W. Mizunoya K. Kishida, K. Inoue, H. Kuriyama, T. Nakamura, et al., Aquaporin 7 deficiency is associated with development of obesity through activation of adipose glycerol kinase, Proc. Natl. Acad. Sci. U.S.A. 102 (2005) 10993-10998, https:// 
doi.org/10.1073/pnas.0503291102

[145] M. Hara-Chikuma, E. Sohara, T. Rai, M. Ikawa, M. Okabe, S. Sasaki, S. Uchida, A.S. Verkman, Progressive adipocyte hypertrophy in aquaporin-7-deficient mice: adipocyte glycerol permeability as a novel regulator of fat accumulation, J. Biol. Chem. 280 (2005) 15493-15496, https://doi.org/10.1074/ jbc.C500028200.

[146] V.N. Civelek, J.A. Hamilton, K. Tornheim, K.L. Kelly, B.E. Corkey, Intracellular $\mathrm{PH}$ in adipocytes: effects of free fatty acid diffusion across the plasma membrane, lipolytic agonists, and insulin, Proc. Natl. Acad. Sci. Unit. States Am. 93 (1996) 10139-10144, https://doi.org/10.1073/pnas.93.19.10139.

[147] S.P. Mukherjee, C. Mukherjee, Metabolic activation of adipocytes by insulin accom panied by an early increase in intracellular pH, Ann. N. Y. Acad. Sci. 372 (1981) 347-351, https://doi.org/10.1111/j.1749-6632.1981.tb15486.x.

[148] A. Klip, T. Ramlal, U.M. Koivisto, Stimulation of $\mathrm{Na}+/ \mathrm{H}+$ exchange by insulin and phorbol ester during differentiation of 3T3-L1 cells. Relation to hexose uptake, Endocrinology 123 (1988) 296-304, https://doi.org/10.1210/endo123-1-296.

[149] H. Meisner, K. Tenney, PH as an indicator of free fatty acid release from adipocytes, J. Lipid Res. 18 (1977) 774-776.

[150] D. Rudman, P.W. Shank, Observations on the production of hydrogen ions during mobilization of fatty acids from adipose tissue, Endocrinology 79 (1966) 1100-1108, https://doi.org/10.1210/endo-79-6-1100.

[151] M.P. Marrades, F.I. Milagro, J.A. Martínez, M.J. Moreno-Aliaga, Differential expression of aquaporin 7 in adipose tissue of lean and obese high fat consumers, Biochem. Biophys. Res. Commun. 339 (2006) 785-789, https:// doi.org/10.1016/j.bbrc.2005.11.080.

[152] V. Ceperuelo-Mallafré, M. Miranda, M.R. Chacón, N. Vilarrasa, A. Megia, C. Gutiérrez, J.M. Fernández-Real, J.M. Gómez, E. Caubet, G. Frühbeck, et al., Adipose tissue expression of the glycerol channel aquaporin-7 gene is altered in severe obesity but not in type 2 diabetes, J. Clin. Endocrinol. Metab. 92 (2007) 3640-3645, https://doi.org/10.1210/jc.2007-0531.

[153] S. Prudente, E. Flex, E. Morini, F. Turchi, D. Capponi, S. De Cosmo, V. Tassi, V. Guida, A. Avogaro, F. Folli, et al., A functional variant of the adipocyte glycerol channel aquaporin 7 gene is associated with obesity and related metabolic abnormalities, Diabetes 56 (2007) 1468-1474, https://doi.org/ $10.2337 / \mathrm{db06}-1389$

[154] V. Catalán, J. Gómez-Ambrosi, C. Pastor, F. Rotellar, C. Silva, A. Rodríguez, M.J. Gil, J.A. Cienfuegos, J. Salvador, J. Vendrell, et al., Influence of morbid obesity and insulin resistance on gene expression levels of AQP7 in visceral adipose tissue and AQP9 in liver, Obes. Surg. 18 (2008) 695-701, https:// doi.org/10.1007/s11695-008-9453-7.

[155] D.A. de Luis, R. Almansa, R. Aller, O. Izaola, E. Romero, Gene expression analysis identify a metabolic and cell function alterations as a hallmark of obesity without metabolic syndrome in peripheral blood, a pilot study, Clin. Nutr. (2017), https://doi.org/10.1016/j.clnu.2017.06.006.

[156] E. Oikonomou, E. Kostopoulou, A.P. Rojas-Gil, G. Georgiou, B.E. Spiliotis, Adipocyte aquaporin 7 (AQP7) expression in lean children and children with obesity. Possible involvement in molecular mechanisms of childhood obesity, J. Pediatr. Endocrinol. Metab. 31 (2018) 1081-1089, https://doi.org/ 10.1515/jpem-2018-0281.

[157] R. Mourelatou, E. Kostopoulou, A.P. Rojas-Gil, I. Kehagias, D. Linos, F.E. Kalfarentzos, B.E. Spiliotis, Decreased adipocyte glucose transporter 4 (GLUT4) and aquaglyceroporin-7 (AQP7) in adults with morbid obesity: possible early markers of metabolic dysfunction, Hormones (Basel) 18 (2019) 297-306, https://doi.org/10.1007/s42000-019-00130-8.

[158] L. Portois, Y. Zhang, J. Perret, K. Louchami, N. Gaspard, E. Hupkens, N. Bolaky, V. Delforge, R. Beauwens, W.J. Malaisse, et al., Glycerol metabolism alteration in adipocytes from N3-PUFA-depleted rats, an animal model for metabolic syndrome, Horm. Metab. Res. 44 (2012) 28-32, https://doi.org/10.1055/s0031-1297942.

[159] R.J.F. Loos, P.T. Katzmarzyk, D.C. Rao, T. Rice, A.S. Leon, J.S. Skinner, J.H. Wilmore, T. Rankinen, C. Bouchard, HERITAGE family study genomewide linkage scan for the metabolic syndrome in the HERITAGE family study, J. Clin. Endocrinol. Metab. 88 (2003) 5935-5943, https://doi.org/ 10.1210/jc.2003-030553.

[160] T.H. Luo, Y. Zhao, G. Li, W.T. Yuan, J.J. Zhao, J.L. Chen, W. Huang, M. Luo, A genome-wide search for type II diabetes susceptibility genes in Chinese hans, Diabetologia 44 (2001) 501-506, https://doi.org/10.1007/ s001250051649.

[161] K. Matsumura, B.H.-J. Chang, M. Fujimiya, W. Chen, R.N. Kulkarni, Y. Eguchi, H. Kimura, H. Kojima, L. Chan, Aquaporin 7 is a beta-cell protein and regulator of intraislet glycerol content and glycerol kinase activity, beta-cell mass, and insulin production and secretion, Mol. Cell Biol. 27 (2007) 6026-6037, https://doi.org/10.1128/MCB.00384-07.

[162] M.T. Skowronski, A. Skowronska, A. Rojek, M.K. Oklinski, S. Nielsen, Prolonged starvation causes up-regulation of AQP1 in adipose tissue capillaries of AQP7 knock-out mice, Int. J. Mol. Sci. 17 (2016), https://doi.org/10.3390/ ijms17071101.

[163] N.E. Boutagy, R.P. McMillan, M.I. Frisard, M.W. Hulver, Metabolic endotoxemia with obesity: is it real and is it relevant? Biochimie 124 (2016) 11-20, https://doi.org/10.1016/j.biochi.2015.06.020.

[164] X. Chen, Q. Yu, Y. Zhu, Y. Bi, W. Sun, H. Liang, M. Cai, X. He, J. Weng, Insulin therapy stimulates lipid synthesis and improves endocrine functions of adipocytes in dietary obese C57BL/6 mice, Acta Pharmacol. Sin. 31 (2010) 341-346, https://doi.org/10.1038/aps.2010.17.
[165] S. Rocha-Rodrigues, A. Rodríguez, S. Becerril, B. Ramírez, I.O. Gonçalves, J. Beleza, G. Frühbeck, A. Ascensão, J. Magalhães, Physical exercise remodels visceral adipose tissue and mitochondrial lipid metabolism in rats fed a highfat diet, Clin. Exp. Pharmacol. Physiol. 44 (2017) 386-394, https://doi.org/ 10.1111/1440-1681.12706.

[166] E.T. Mehanna, B.M. Barakat, M.H. ElSayed, M.K. Tawfik, An optimized dose of raspberry ketones controls hyperlipidemia and insulin resistance in male obese rats: effect on adipose tissue expression of adipocytokines and aquaporin 7, Eur. J. Pharmacol. 832 (2018) 81-89, https://doi.org/10.1016/ j.ejphar.2018.05.028.

[167] G. Uriarte, L. Paternain, F.I. Milagro, J.A. Martínez, J. Campion, Shifting to a control diet after a high-fat, high-sucrose diet intake induces epigenetic changes in retroperitoneal adipocytes of wistar rats, J. Physiol. Biochem. 69 (2013) 601-611, https://doi.org/10.1007/s13105-012-0231-6.

[168] R. Jain, E. Lammert, Cell-cell interactions in the endocrine pancreas, Diabetes Obes. Metabol. 11 (Suppl 4) (2009) 159-167, https://doi.org/10.1111/j.14631326.2009.01102.x.

[169] K.M. Andralojc, A. Mercalli, K.W. Nowak, L. Albarello, R. Calcagno, L. Luzi, E. Bonifacio, C. Doglioni, L. Piemonti, Ghrelin-producing epsilon cells in the developing and adult human pancreas, Diabetologia 52 (2009) 486-493, https://doi.org/10.1007/s00125-008-1238-y.

[170] D.J. Steiner, A. Kim, K. Miller, M. Hara, Pancreatic islet plasticity: interspecies comparison of islet architecture and composition, Islets 2 (2010) 135-145, https://doi.org/10.4161/isl.2.3.11815.

[171] G. Da Silva Xavier, The cells of the islets of Langerhans, J. Clin. Med. 7 (2018), https://doi.org/10.3390/jcm7030054.

[172] J. Dolenšek, M.S. Rupnik, A. Stožer, Structural similarities and differences between the human and the mouse pancreas, Islets 7 (2015), e1024405, https://doi.org/10.1080/19382014.2015.1024405.

[173] L. Méndez-Giménez, S. Becerril, S.P. Camões, I.V. da Silva, C. Rodrigues, R. Moncada, V. Valentí, V. Catalán, J. Gómez-Ambrosi, J.P. Miranda, et al., Role of aquaporin-7 in ghrelin- and GLP-1-induced improvement of pancreatic $\beta$ cell function after sleeve gastrectomy in obese rats, Int. J. Obes. 41 (2017) 1394-1402, https://doi.org/10.1038/ijo.2017.135.

[174] J.C. Henquin, Regulation of insulin secretion: a matter of phase control and amplitude modulation, Diabetologia 52 (2009) 739-751, https://doi.org/ 10.1007/s00125-009-1314-y.

[175] H.E. Miley, E.A. Sheader, P.D. Brown, L. Best, Glucose-induced swelling in rat pancreatic beta-cells, J. Physiol. (Lond.) 504 (Pt 1) (1997) 191-198.

[176] L. Best, H.E. Miley, A.P. Yates, Activation of an anion conductance and betacell depolarization during hypotonically induced insulin release, Exp. Physiol. 81 (1996) 927-933.

[177] G. Drews, P. Krippeit-Drews, M. Düfer, Electrophysiology of islet cells, Adv. Exp. Med. Biol. 654 (2010) 115-163, https://doi.org/10.1007/978-90-4813271-3_7.

[178] M. Virreira, J. Perret, C. Delporte, Pancreatic beta-cells: role of glycerol and aquaglyceroporin 7, Int. J. Biochem. Cell Biol. 43 (2011) 10-13, https:// doi.org/10.1016/j.biocel.2010.10.018.

[179] H. Mulder, S. Yang, M.S. Winzell, C. Holm, B. Ahrén, Inhibition of lipase activity and lipolysis in rat islets reduces insulin secretion, Diabetes 53 (2004) $122-128$.

[180] M.S. Winzell, K. Ström, C. Holm, B. Ahrén, Glucose-stimulated insulin secretion correlates with beta-cell lipolysis, Nutr. Metabol. Cardiovasc. Dis. 16 (Suppl 1) (2006) S11-S16, https://doi.org/10.1016/j.numecd.2005.11.006.

[181] G.C. Yaney, B.E. Corkey, Fatty acid metabolism and insulin secretion in pancreatic beta cells, Diabetologia 46 (2003) 1297-1312, https://doi.org/ 10.1007/s00125-003-1207-4.

[182] A.S. Verkman, M.O. Anderson, M.C. Papadopoulos, Aquaporins: important but elusive drug targets, Nat. Rev. Drug Discov. 13 (2014) 259-277, https:// doi.org/10.1038/nrd4226.

[183] M. Abir-Awan, P. Kitchen, M.M. Salman, M.T. Conner, A.C. Conner, R.M. Bill, Inhibitors of mammalian aquaporin water channels, Int. J. Mol. Sci. 20 (2019), https://doi.org/10.3390/ijms20071589.

[184] M. Zelenina, S. Tritto, A.A. Bondar, S. Zelenin, A. Aperia, Copper inhibits the water and glycerol permeability of aquaporin-3, J. Biol. Chem. 279 (2004) 51939-51943, https://doi.org/10.1074/jbc.M407645200.

[185] A.P. Martins, A. Marrone, A. Ciancetta, A. Galán Cobo, M. Echevarría, T.F. Moura, N. Re, A. Casini, G. Soveral, Targeting aquaporin function: potent inhibition of aquaglyceroporin-3 by a gold-based compound, PloS One 7 (2012), e37435, https://doi.org/10.1371/journal.pone.0037435.

[186] A. Madeira, A. de Almeida, C. de Graaf, M. Camps, A. Zorzano, T.F. Moura, A. Casini, G. Soveral, A gold coordination compound as a chemical probe to unravel aquaporin-7 function, Chembiochem 15 (2014) 1487-1494, https:// doi.org/10.1002/cbic.201402103.

[187] A.P. Martins, A. Ciancetta, A. de Almeida, A. Marrone, N. Re, G. Soveral, A. Casini, Aquaporin inhibition by gold(III) compounds: new insights, ChemMedChem 8 (2013) 1086-1092, https://doi.org/10.1002/ cmdc.201300107.

[188] V. Graziani, A. Marrone, N. Re, C. Coletti, J.A. Platts, A. Casini, A multi-level theoretical study to disclose the binding mechanisms of gold(III)-Bipyridyl compounds as selective aquaglyceroporin inhibitors, Chemistry 23 (2017) 13802-13813, https://doi.org/10.1002/chem.201703092.

[189] G. Soveral, A. Casini, Aquaporin modulators: a patent review (2010-2015), Expert Opin. Ther. Pat. 27 (2017) 49-62, https://doi.org/10.1080/ 13543776.2017.1236085. 
[190] H. Tsukaguchi, C. Shayakul, U.V. Berger, B. Mackenzie, S. Devidas, W.B. Guggino, A.N. van Hoek, M.A. Hediger, Molecular characterization of a broad selectivity neutral solute channel, J. Biol. Chem. 273 (1998) $24737-24743$.
[191] S.J. Wacker, C. Aponte-Santamaría, P. Kjellbom, S. Nielsen, B.L. de Groot, M. Rützler, The identification of novel, high affinity AQP9 inhibitors in an intracellular binding site, Mol. Membr. Biol. 30 (2013) 246-260, https:// doi.org/10.3109/09687688.2013.773095. 